UNIVERSIDADE DE SÃO PAULO

ESCOLA DE ARTES, CIÊNCIAS E HUMANIDADES

PROGRAMA DE PÓS-GRADUAÇÃO EM SISTEMAS DE INFORMAÇÃO

ELTHON MANHAS DE FREITAS

Planejamento probabilístico sensível a risco com ILAO* e função utilidade exponencial

São Paulo

2019 


\section{Planejamento probabilístico sensível a risco com ILAO* e função utilidade exponencial}

Versão corrigida

Dissertação apresentada à Escola de Artes, Ciências e Humanidades da Universidade de São Paulo para obtenção do título de Mestre em Ciências pelo Programa de Pós-graduação em Sistemas de Informação.

Área de concentração: Metodologia e Técnicas da Computação

Versão corrigida contendo as alterações solicitadas pela comissão julgadora em 18 de outubro de 2018. A versão original encontrase em acervo reservado na Biblioteca da EACH-USP e na Biblioteca Digital de Teses e Dissertações da USP (BDTD), de acordo com a Resolução CoPGr 6018, de 13 de outubro de 2011.

Orientadora: Profa. Dra. Karina Valdivia Delgado

São Paulo 
Autorizo a reprodução e divulgação total ou parcial deste trabalho, por qualquer meio convencional ou eletrônico, para fins de estudo e pesquisa, desde que citada a fonte.

CATALOGAÇÃO-NA-PUBLICAÇÃO

(Universidade de São Paulo. Escola de Artes, Ciências e Humanidades. Biblioteca) CRB-8 4936

Freitas, Elthon Manhas de

Planejamento probabilístico sensível a risco com ILAO* e função utilidade exponencial / Elthon Manhas de Freitas ; orientadora, Karina Valdivia Delgado. - 2019.

57 f. : il.

Dissertação (Mestrado em Ciências) - Programa de PósGraduação em Sistemas de Informação, Escola de Artes, Ciências e Humanidades, Universidade de São Paulo, em 2018.

Versão corrigida

1. Estatística para inteligência artificial. 2. Processos de Markov. 3. Processos estocásticos. 4. Programação heurística. I. Delgado, Karina Valdivia, orient. II. Titulo. 
Dissertação de autoria de Elthon Manhas de Freitas, sob o título "Planejamento probabilístico sensível a risco com ILAO* e função utilidade exponencial", apresentada à Escola de Artes, Ciências e Humanidades da Universidade de São Paulo, para obtenção do título de Mestre em Ciências pelo Programa de Pós-graduação em Sistemas de Informação, na área de concentração Metodologia e Técnicas da Computação, aprovada em 18 de outubro de 2018 pela comissão examinadora constituída pelos doutores:

Profa. Dra. Karina Valdivia Delgado

Instituição: Universidade de São Paulo

Presidente

Prof. Dr. Carlos Henrique Costa Ribeiro

Instituição: Instituto Tecnológico de Aeronáutica

Prof. Dr. Fernando Fagundes Ferreira

Instituição: Universidade de São Paulo

Profa. Dra. Patrícia Rufino Oliveira

Instituição: Universidade de São Paulo 
Ao Henrique; meu filho, com amor e gratidão por dar sentido à minha existência.

À Elizabeth e Enivaldo; meus pais, por serem meus exemplos, pelo amor e apoio. 


\section{Agradecimentos}

A realização deste mestrado contou com importantes apoios e incentivos, sem os quais não teriam se tornado uma realidade e aos quais estarei eternamento grato.

À professora Karina Valdivia Delgado, pelos ensinamentos e orientação, por acreditar em mim quando eu mais precisei, por sempre me ouvir com respeito, pela sua dedicação, pelo seu desprendimento em me ajudar e me apoiar, por seus exemplos de vida e sua amizade. Não consigo colocar em palavras o quanto a admiro como ser humano. Sempre preocupada com meu desenvolvimento acadêmico, profissional e pessoal e sempre cobrando o melhor de mim, por isso a considero como alguém da minha família.

Ao professor Valdinei Freire da Silva, pelas horas que pacientemente me ensinou sobre as teorias necessárias para concluir este trabalho, acompanhou meu progresso e evolução, validou e corrigiu os resultados de meus experimentos, celebrou minhas pequenas conquistas e retificou meus caminhos todas as vezes que foi necessário. Seus trabalhos anteriores serviram de base e motivação para minha pesquisa e sua dedicação em trabalhar comigo foi tamanha tanto quanto a dedicação de um orientador.

Ao meu irmão Elber, por despertar em mim todo o amor e admiração e por ser um exemplo de retidão, paciência e companheirismo.

Aos amigos e aos colegas do Programa de Pós-graduação em Sistemas de Informação (PPgSI) da EACH pela estima e companheirismo em meio aos muitos almoços e cafés compartilhando experiências e aprendizados.

À Keylla, por estar sempre ao meu lado, pelo amor e compreensão.

À CAPES (Coordenação de Aperfeiçoamento de Pessoal de Nível Superior) pela concessão da bolsa durante parte do período de realização deste mestrado.

Aos participantes da banca de qualificação pelas observações e direcionamentos que me auxiliaram a guiar este trabalho e pela participação da banca examinadora de defesa.

E, finalmente, agradeço à Deus pela minha vida, pela paz nos momentos em que me encontrei incapaz de prosseguir e pela força que me fez superar obstáculos e dificuldades e concluir com êxito este mestrado. 
"Existem muitas hipóteses em ciência que estão erradas. Isso é perfeitamente aceitável, elas são a abertura para achar as que estão certas..."

(Carl Sagan) "Por vezes sentimos que aquilo que fazemos não é senão uma gota de água no mar. Mas o mar seria menor se lhe faltasse uma gota..." (Madre Teresa de Calcuta) 


\section{Resumo}

FREITAS, Elthon Manhas de. Planejamento probabilístico sensível a risco com ILAO* e função utilidade exponencial. 2019. 57 f. Dissertação (Mestrado em Ciências) - Escola de Artes, Ciências e Humanidades, Universidade de São Paulo, São Paulo, 2018.

Os processos de decisão de Markov (Markov Decision Process - MDP) têm sido usados para resolução de problemas de tomada de decisão sequencial. Existem problemas em que lidar com os riscos do ambiente para obter um resultado confiável é mais importante do que maximizar o retorno médio esperado. MDPs que lidam com esse tipo de problemas são chamados de processos de decisão de Markov sensíveis a risco (Risk-Sensitive Markov Decision Process - RSMDP). Dentre as diversas variações de RSMDP, estão os trabalhos baseados em utilidade exponencial que utilizam um fator de risco, o qual modela a atitude a risco do agente e que pode ser propensa ou aversa. Os algoritmos existentes na literatura para resolver esse tipo de RSMDPs são ineficientes se comparados a outros algoritmos de MDP. Neste projeto, é apresentada uma solução que pode ser usada em problemas maiores, tanto por executar cálculos apenas em estados relevantes para atingir um conjunto de estados meta partindo de um estado inicial, quanto por permitir processamento de números com expoentes muito elevados para os ambientes computacionais atuais. Os experimentos realizados evidenciam que (i) o algoritmo proposto é mais eficiente, se comparado aos algoritmos estado-da-arte para RSMDPs; e (ii) o uso da técnica LogSumExp permite resolver o problema de trabalhar com expoentes muito elevados em RSMDPs.

Palavras-chave: Processos de decisão de Markov. Sensibilidade a risco. Aversão a risco. Planejamento probabilístico. Utilidade exponencial. 


\begin{abstract}
FREITAS, Elthon Manhas de. Probabilistic risk-sensitive planning with ILAO* and exponential utility function. 2019. 57 p. Dissertation (Master of Science) School of Arts, Sciences and Humanities, University of São Paulo, São Paulo, 2018.

Markov Decision Process (MDP) has been used very efficiently to solve sequential decisionmaking problems. There are problems where dealing with environmental risks to get a reliable result is more important than maximizing the expected average return. MDPs that deal with this type of problem are called risk-sensitive Markov decision processes (RSMDP). Among the several variations of RSMDP are the works based on exponential utility that use a risk factor, which models the agent's risk attitude that can be prone or averse. The algorithms in the literature to solve this type of RSMDPs are inefficient when compared to other MDP algorithms. In this project, a solution is presented that can be used in larger problems, either by performing calculations only in relevant states to reach a set of meta states starting from an initial state, or by allowing the processing of numbers with very high exponents for the current computational environments. The experiments show that (i) the proposed algorithm is more efficient when compared to state-of-the-art algorithms for RSMDPs; and (ii) the LogSumExp technique solves the problem of working with very large exponents in RSMDPs.
\end{abstract}

Keywords: Markov decision process. Risk sensitive. Risk averse. Probabilistic planning. Exponential utility. 


\section{Lista de figuras}

Figura 1 - Representação gráfica de um GDMDP com 3 estados e 2 ações. . . . . 21

Figura 2 - Estados e transições no Problema 1 de Travessia do Rio em um grid de tamanho $3 \times 3 . \ldots \ldots \ldots . \ldots \ldots$

Figura 3 - Principais passos do algoritmo RS-ILAO* para um domínio da Travessia do Rio com um grid de tamanho $3 \times 3 \ldots . . \ldots 36$

Figura 4 - Análise da função exp sobre a variável risco $\times$ custo imediato $\beta c$ (eixo da esquerda) e da função de logaritmo natural aplicada à função exponencial

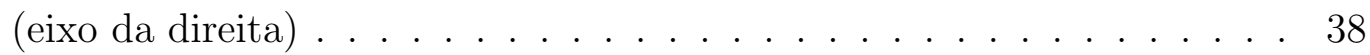

Figura 5 - Travessia do rio com grid $14 \times 5$ e seu mapeamento em estados . . . 41

Figura 6 - Probabilidades das ações para $s=2 h \ldots \ldots \ldots$. . . . . . 42

Figura 7 - Tempo médio de convergência para o Domínio de Travessia do Rio . . 48

Figura 8 - Tempo médio de convergência para o Domínio de Travessia do Rio utilizando heurísticas diferentes para o RS-ILAO* . . . . . . . . . . 49

Figura 9 - Tempo médio de convergência para o Domínio de Travessia do Rio $20 \times 8$ utilizando fatores de risco diferentes para o algoritmo RS-ILAO* 50

Figura 10 - Tempo médio de convergência para o Domínio de Travessia do Rio utilizando Iteração de Valor Sensível a Risco e Iteração de Valor Sensível a Risco com a estratégia LogSumExp . . . . . . . . . . . . . . . 52 


\section{Lista de algoritmos}

Algoritmo 1 - Iteração de Política para GDMDP . . . . . . . . . . . . . . . . . . 23

Algoritmo 2 - Iteração de Valor para GDMDP . . . . . . . . . . . . . . . . . . . . . . . . 24

Algoritmo 3 - Algoritmo de Iteração de Política Sensível a Risco . . . . . . . . . . . . . 27

Algoritmo 4 - : RS-ILAO* para GDRSMDP Sensível ao Risco . . . . . . . . . . . . . . 30

Algoritmo 5 - : Busca em Profundidade para RS-ILAO * . . . . . . . . . . . . 31

Algoritmo 6 - : Verificação de convergência do RS-ILAO* . . . . . . . . . . . . . . . . . 32

Algoritmo 7 - : Função utilidade exponencial para RS-ILAO* . . . . . . . . . . . . . . 32

Algoritmo 8 - : Função de expansão para RS-ILAO* . . . . . . . . . . . . . . . . . . . . . 32 


\section{Lista de tabelas}

Tabela 1 - Políticas encontradas pelos algoritmos Iteração de Política Sensível a Risco e Iteração de Valor Sensível a Risco para o domínio Travessia do Rio em um grid $14 \times 5$ com fatores de risco $\beta$ distintos . . . . . . . . 44

Tabela 2 - Políticas encontradas pelo algoritmo RS-ILAO* para o domínio Travessia do Rio em um grid $14 \times 5$ com fatores de risco $\beta$ distintos . . . . . 45

Tabela 3 - Políticas encontradas pelo algoritmo RS-ILAO* para o domínio Travessia do Rio em um grid $20 \times 7$ com fatores de risco $\beta$ distintos . . . . . 46

Tabela 4 - Políticas encontradas pelos algoritmos de Iteração de Política Sensível a Risco e Iteração de Valor Sensível a Risco para o domínio Carteira de Motorista com fatores de risco $\beta$ distintos . . . . . . . . . . . . 47

Tabela 5 - Políticas encontradas pelo algoritmo RS-ILAO* para o domínio Carteira de Motorista com fatores de risco $\beta$ distintos e com estado inicial $s_{0}=4 h \quad 47$ 


\section{Lista de abreviaturas e siglas}

A* A-estrela, um algoritmo tradicional de busca de caminho

AO* $\quad$ AO-estrela, uma extensão do algoritmo $\mathrm{A}^{*}$

GDMDP Processo de decisão de Markov dirigido à meta

GDRSMDP Processo de decisão de Markov dirigido à meta e sensível a risco

ILAO* ILAO-estrela, uma evolução do algoritmo LAO*

IP Iteração de política

IV Iteração de valor

LAO* LAO-estrela, uma extensão do algoritmo tradicional AO* que permite trabalhar com laços

LSE LogSumExp - Técnica de aproximação que utiliza função logaritímica, função somatória e função exponencial

MDP Processo de decisão de Markov

RS-ILAO* Algoritmo ILAO* sensível ao risco, proposto neste trabalho

RSMDP Processo de decisão de Markov sensível a risco 


\section{Lista de símbolos}

$S$

$s$

A

$a$

$T$

$c$

$S_{g}$

$C^{\pi}$

$\leq$

1

$\epsilon$

$\subset$

$\Pi$

$\pi$

$\lim () \quad$ Função limite

$\infty \quad$ Infinito

$\sum() \quad$ sigma - Função somatória

$\mathbb{R}$

$\mathbb{R}^{+}$

$\rightarrow$

$\mathrm{E}$

$u()$

Menor ou igual que

Tal que

Pertence

Contém

pi - Política estacionária

Implica

Função esperança

Função utilidade
Um conjunto de estados de um MDP

Um estado pertencente ao MDP

Um conjunto de ações de um MDP

Uma ação pertencente ao MDP

Uma função de transição probabilística de um MDP

Uma função de custo de um MDP

Um conjunto de estados meta de um MDP

Custo total de execução da política $\pi$

$p i$ - Conjunto de políticas estacionárias

Conjunto dos números reais

Conjunto dos números reais não negativos 


\begin{tabular}{|c|c|}
\hline$V()$ & Função valor \\
\hline$V^{\pi}()$ & Função valor da política $\pi$ \\
\hline$L()$ & Função valor utilizando aproximação pela técnica $\operatorname{LogSumExp}$ \\
\hline$L^{\pi}()$ & $\begin{array}{l}\text { Função valor da política estacionária } \pi \text { utilizando aproximação pela } \\
\text { técnica LogSumExp }\end{array}$ \\
\hline$|S|$ & Tamanho do conjunto de estados $S$ \\
\hline$T^{\pi}$ & Matriz de transição da política $\pi$ \\
\hline $\mathbf{T}_{G^{c}}^{\pi}$ & Matriz de transição da política $\pi$ em um MDP dirigido à meta \\
\hline$\cup$ & União \\
\hline$\forall$ & Para todo elemento do conjunto; Para qualquer elemento do conjunto \\
\hline $\min ()$ & Função do menor valor de um conjunto \\
\hline $\arg \min ()$ & Função d menor valor de um conjunto \\
\hline$G^{\prime}$ & Grafo expandido \\
\hline$G^{\prime \prime}$ & Grafo de melhor solução \\
\hline $\bar{C}^{\pi}$ & Equivalente de certeza \\
\hline$\tilde{C}^{\pi}$ & Custo esperado \\
\hline$\rho()$ & rho - Função de raio espectral \\
\hline$\beta$ & beta - Fator de risco \\
\hline $\operatorname{sgn}()$ & Função sinal de um número \\
\hline $\exp ()$ & Função exponencial \\
\hline$h()$ & Função heurística \\
\hline $\ln ()$ & Função de logaritmo natural \\
\hline
\end{tabular}




\section{Sumário}

Introdução . . . . . . . . . . . . . . . . 17

$1.1 \quad$ Objetivo principal . . . . . . . . . . . . . . . 19

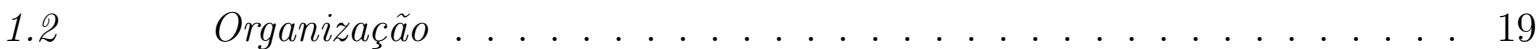

Conceitos fundamentais .............. 20

2.1 Processo de decisão de Markov dirigido à meta . . . . . . . . . . . . 20

2.1.1 Avaliação de uma política de um GDMDP . . . . . . . . . . . . . 21

2.1.2 Política ótima . . . . . . . . . . . . . . . . 23

2.1.3 Algoritmo de Iteração de Política . . . . . . . . . . . . . . 23

2.1.4 Algoritmo de Iteração de Valor . . . . . . . . . . . . . . . . . 24

2.1.5 Algoritmo ILAO* . . . . . . . . . . . . . . . . . . 24

2.2 Atitudes em relação ao risco . . . . . . . . . . . . . . . . . 25

2.3 MDP Sensível a Risco e Dirigido a Meta . . . . . . . . . . . . 26

2.3.1 Algoritmo de Iteração de Política Sensível a Risco . . . . . . . . . . 27

2.3.2 Algoritmo de Iteração de Valor Sensível a Risco . . . . . . . . . . . 28

ILAO* Sensível a Risco . . . . . . . . . . . . . 29

Convergência ............................ 33

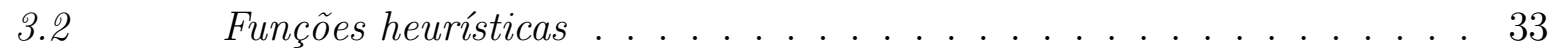

3.3 Exemplo de execução do algoritmo $R S-I L A O^{*} \ldots \ldots . \ldots . \ldots$

$4 \quad$ Estratégia LogSumExp para GDRSMDP . . . . . . . . . 37

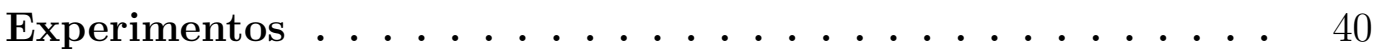

5.1 Dominio da travessia do rio . . . . . . . . . . . . . . . . 40

5.2 Dominio da carteira de motorista . . . . . . . . . . . . . . . 41

5.3 Avaliação dos algoritmo RS-ILAO* . . . . . . . . . . . 42

5.3.1 Políticas obtidas . . . . . . . . . . . . . . . . 43

5.3.2 Tempo de convergência para fator de risco fixo e heurística fixa . . 48

5.3.3 Tempo de convergência usando diferentes heurísticas . . . . . . . . 48

5.3.4 Tempo de convergência usando diferentes fatores de risco . . . . . . 50

$5.4 \quad$ Avaliação da estratégia LogSumExp . . . . . . . . . . . . . . . 51 
Conclusões e trabalhos futuros . . . . . . . . . . . . 53

6.1

Resumo das contribuições.................. 53

6.2

Publicações geradas . . . . . . . . . . . . . . . . . . . 53

6.3

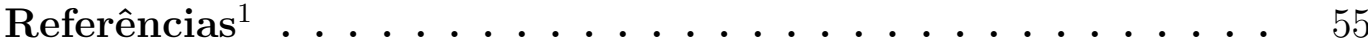




\section{Introdução}

Processo de decisão de Markov (Markov Decision Process - MDP) é um modelo matemático utilizado para tomada de decisão sequencial baseada apenas nas informações do estado atual do ambiente (PUTERMAN, 1994). Este modelo é classificado como estocástico pois não há controle de todas as variáveis presentes no ambiente em que o agente tomador de decisão está inserido. A incerteza nesses processos pode ocorrer por diversos fatores como imprecisão durante a execução de uma ação ou ainda pela existência de outros agentes que podem estar constantemente interferindo no sistema.

A maioria dos trabalhos em MDPs avalia o efeito probabilístico na execução de ações no sistema e têm como objetivo gerar uma política, a ser seguida por um agente executor, de modo a maximizar a recompensa esperada do sistema ou minimizar o custo esperado (DELAGE; MANNOR, 2010) pois ao longo de sucessivas execuções, o sistema tende gerar um valor médio muito próximo ao valor esperado.

Porém, há problemas da vida real que só podem ser executados apenas uma vez. Por exemplo, um veículo com navegação autônoma tem que considerar que cada trajeto é único e não irá se repetir, logo o processo não poderá simplesmente reiniciar em caso de falha. Realizar um transplante de coração é outro exemplo em que aumentar as chances de sucesso se faz tão importante que aumentos de custo são aceitos quase sem questionamento. Outros problemas tem uma duração tão longa que não podem ser executados várias vezes, como realizar uma viagem a Marte, investir para a aposentadoria de uma vida (MOLDOVAN; ABBEEL, 2012) ou implantar um grande projeto empresarial. Estes são alguns exemplos em que mitigar, evitar e até eliminar os riscos do ambiente é muito mais importante do que maximizar o retorno esperado. Estes são problemas de máxima aversão ao risco e para este extremo existe uma otimização denominada minmax, que minimiza o custo considerando o pior caso.

Exceto pelos casos extremos, o cotidiano é pautado por aversão e propensão ao risco. Um piloto de corrida está disposto a forçar um pouco mais o carro na última volta para conseguir melhorar sua posição, assim como as pessoas estão dispostas a conhecer um lugar novo em busca de novas experiências. Devemos considerar também que pessoas diferentes têm níveis de aceitação diferentes de risco, até mesmo momentos distintos podem afetar e tornar a pessoa mais propensa ou mais aversa ao risco. 
Problema 1: Travessia do rio (FREIRE; DELGADO, 2017): No problema da travessia do rio, uma pessoa está em uma margem do rio e deseja chegar a um ponto específico da outra margem. O problema do rio é modelado em um mapa $n \times m$, em que $n$ é o número de linhas $m$, o número de colunas. Esta pessoa tem duas opções de travessia. A primeira opção é andar y $(0 \leq y \leq 9.999)$ metros em direção ao norte e então atravessar o rio a nado. A segunda opção é andar 10.000 metros ao norte, onde há uma ponte que pode ser usada para a travessia até a outra margem. Devido a imprevistos no ambiente, cada ação de andar um metro tem 99\% de chance de ser bem sucedido e $1 \%$ de chance de ficar parado devido algum imprevisto encontrado pelo caminho. Em y $=1$ há uma perigosa cachoeira, em que a pessoa tem $100 \%$ de chance de se afogar. Em outras posições do rio $\langle x, y\rangle$, se a pessoa decidir nadar, há $80 \%$ de chance de alcançar a posição $\langle x+1, y\rangle$ e $20 \%$ de chace da pessoa ir parar na posição $\langle x, y-1\rangle$ devido a correnteza do rio. O custo da ação andar é 4 e da ação nadar é 1. Veja que neste problema, quanto mais a pessoa andar para longe da cachoeira, menor o risco de se afogar na cachoeira.

Para lidar com problemas deste tipo, há uma pequena parcela de trabalhos que avaliam a sensibilidade e a tolerância ao risco e de alguma forma consideram estes parâmetros em seus modelos, os chamados Processos de Decisão de Markov Sensíveis ao Risco (Risk Sensitive Markov Decision Process - RSMDP). Existem vários critérios que podem ser usados para lidar com risco, entre eles, o critério que usa a utilidade exponencial esperada (HOWARD; MATHESON, 1972; JAQUETTE, 1976; DENARDO; ROTHBLUM, 1979; ROTHBLUM, 1984; PATEK, 2001; FREIRE; DELGADO, 2016), ponderação entre esperança e variância (SOBEL, 1982; FILAR; KALLENBERG; LEE, 1989) e estimação de desempenho em um intervalo de confiança (FILAR et al., 1995).

Nos trabalhos baseados em utilidade exponencial esperada é necessário especificar um fator de risco, sendo que os valores factíveis para esse fator de risco dependem do problema de decisão em questão (PATEK, 2001). Em (PATEK, 2001) são provadas as condições para existência de políticas ótimas e um algoritmo de Iteração de Política para MDPs dirigidos à meta que usam o critério de utilidade exponencial esperada, chamados de RSMDPs dirigidos à meta (Goal Directed Risk Sensitive Markov Decision Process GDRSMDP). Porém, uma vez que o algoritmo de Iteração de Política Sensível a Risco avalia o conjunto completo de estados em cada iteração, ele pode ser ineficiente para resolver problemas com um número grande de estados. 
Quando os modelos teóricos que utilizam função exponencial em GDRSMDPs são implementados, temos como resultado números de expoentes muito elevados o que limita sua utilização nos ambientes computacionais atuais. Além disso, na revisão sistemática da literatura de (FREITAS; DELGADO; FREIRE, 2017) não foi encontrada nenhuma solução para esse tipo de GDRSMDPs que permita lidar com números de expoentes muito grandes.

\subsection{Objetivo principal}

Esta pesquisa tem por objetivo (i) projetar um algoritmo mais eficiente e que encontra a política ótima para MDPs dirigidos à meta e sensíveis a risco que utilizam a função utilidade exponencial; e (ii) projetar uma estratégia para superar a limitação causada por expoentes muito elevados quando algoritmos para resolver esse tipo de MDPs são implementados em alguma linguagem de programação.

\subsection{Organização}

O restante deste texto está organizado da seguinte forma. O Capítulo 2 apresenta os principais conceitos e os fundamentos teóricos de processos de decisão de Markov dirigidos à meta, processos de decisão de Markov sensíveis a risco e os algoritmos para resolvê-los.

O Capítulo 3 apresenta a proposta de um novo algoritmo nomeado RS-ILAO* - ILAO* Sensível a Risco - que utiliza a função utilidade exponencial como principal componente modelador da atitude sensível a risco. O Capítulo 4 apresenta uma proposta de utilização da técnica chamada LogSumExp em GDRSMDPs.

O Capítulo 5 apresenta os principais resultados obtidos nos experimentos realizados e o Capítulo 6 traz a conclusão deste trabalho, juntamente com os trabalhos futuros. 


\section{Conceitos fundamentais}

Este trabalho teve como base obras feitas por diversos autores ao longo dos anos. Nas próximas seções deste capítulo serão apresentados os principais conceitos para que seja possível compreender a solução proposta, desde sua elaboração até a sua conclusão.

\subsection{Processo de decisão de Markov dirigido à meta}

Um MDP dirigido a meta (BERTSEKAS; TSITSIKLIS, 1991; GEFFNER; BONET, 2013) (Goal-Directed MDP - GDMDP) é uma tupla $G D M D P=\left(S, A, T, c, S_{g}\right)$, em que:

- $S$ é um conjunto finito de estados observáveis;

- $A$ é um conjunto finito de ações;

- $T\left(s^{\prime} \mid s, a\right)$ é a função probabilística de transição que descreve os efeitos da execução de uma ação $a \in A$ em um estado $s \in S$ resultando em um estado $s^{\prime} \in S$;

- $c(s, a)$ é a função custo de executar uma ação $a \in A$ em um estado $s \in S$; e

- $S_{g} \subset S$ é um conjunto finito de estados meta. Todo estado meta é absorvente, isto é, $T(s \mid s, a)=1$ e $c(s, a)=0$ para qualquer $a \in A, s \in S_{g}$.

O problema de um MDP dirigido à meta define um processo dinâmico discreto em que, em qualquer momento $t$, o agente observa um estado $s_{t}$, executa uma ação $a_{t}$, transita para um estado $s_{t+1}$ após pagar um custo $c_{t}$. Este processo define um horizonte indeterminado, dado que o processo termina após atingir qualquer estado meta em $S_{g}$, e o número de passos que o agente tem para agir não é conhecido a priori. O objetivo de um problema de MDP dirigido à meta é alcançar o estado meta com o mínimo custo acumulado esperado, o qual é considerado um critério neutro a risco.

Uma política estacionária $\pi$ é um mapeamento de estados em ações $(\pi: S \rightarrow A)$ que representa quais ações devem ser executadas em cada estado. O conjunto de políticas estacionárias é representado por П. A execução de uma política estacionária $\pi$ define uma variável aleatória $C^{\pi}$ que representa o custo total de execução da política, e é definido por:

$$
C^{\pi}=\lim _{M \rightarrow \infty} \sum_{t=0}^{M} c_{t}=\lim _{M \rightarrow \infty} \sum_{t=0}^{M} c\left(s_{t}, \pi\left(s_{t}\right)\right) .
$$


A Figura 1 mostra um exemplo de GDMDP. A Figura 1(a) representa o GDMDP como um grafo direcionado com 3 estados $s_{0}, s_{1}$, e $s_{g}$ e 2 ações possíveis $a_{1}$ e $a_{2}$. A Figura 1(b) apresenta os valores da função custo $c$ e a Figura 1(c) apresenta os valores da função de transição $T$. Nesta figura, todas as ações aplicadas em $s_{0}$ são probabilísticas e todas as ações aplicadas em $s_{1}$ são determinísticas. Neste exemplo, $s_{g}$ é o estado meta.

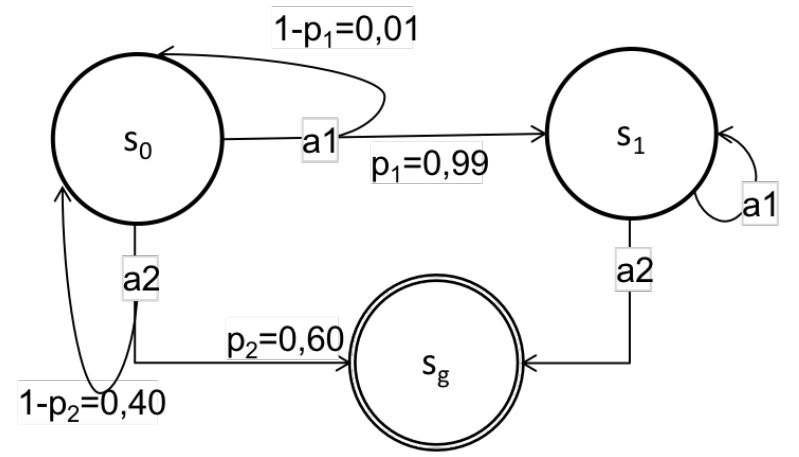

(a)

\begin{tabular}{l|l}
\hline \multicolumn{2}{c}{ função c } \\
\hline$c(s 0, a 1)$ & 4,0 \\
$c(s 0, a 2)$ & 3,0 \\
$c(s 1, a 1)$ & 1,0 \\
$c(s 1, a 2)$ & 1,0 \\
\hline
\end{tabular}

(b)

\begin{tabular}{c|c}
\hline \multicolumn{2}{c}{ função $T$} \\
\hline$T\left(s_{0} \mid s_{0}, a_{1}\right)$ & 0,01 \\
$T\left(s_{1} \mid s_{0}, a_{1}\right)$ & 0,99 \\
$T\left(s_{0} \mid s_{0}, a_{2}\right)$ & 0,40 \\
$T\left(s_{g} \mid s_{0}, a_{2}\right)$ & 0,60 \\
$T\left(s_{1} \mid s_{1}, a_{1}\right)$ & 1,00 \\
$T\left(s_{g} \mid s_{1}, a_{2}\right)$ & 1,00 \\
\hline
\end{tabular}

(c)

Figura 1 - Representação gráfica de um GDMDP com 3 estados e 2 ações. Fonte: Elthon Manhas de Freitas, 2018

\subsubsection{Avaliação de uma política de um GDMDP}

A solução de um MDP dirigido a meta é uma política estacionária $\pi$. Para encontrar uma política ótima, uma função de utilidade $u\left(\mathbb{R}^{+}\right) \rightarrow \mathbb{R}$ deve ser definida, bem como a função valor de uma política, chamada de $V^{\pi}(s)$. O valor $V^{\pi}(s)$ é definido pela esperança da utilidade:

$$
V^{\pi}(s)=\mathrm{E}\left[u\left(C^{\pi}\right) \mid \pi, s_{0}=s\right]
$$

em que E representa a esperança quando a política $\pi$ é executada.

No caso de GDMDPs é usada a função utilidade identidade $u(x)=x$ e usualmente é definido o valor da função por:

$$
V^{\pi}(s)=\lim _{M \rightarrow \infty} \mathrm{E}\left[\sum_{t=0}^{M} c\left(s_{t}, \pi\left(s_{t}\right)\right) \mid \pi, s_{0}=s\right]
$$


O valor da política $\pi$ para o estado $s$ pode ser obtido resolvendo o seguinte sistema de equações:

$$
V^{\pi}(s)= \begin{cases}0 & , \text { se } s \in S_{g} \\ c(s, \pi(s))+\sum_{s^{\prime} \in \mathcal{S}} T\left(s^{\prime} \mid s, \pi(s)\right) V^{\pi}\left(s^{\prime}\right) & , \text { nos demais casos }\end{cases}
$$

ou em sua forma matricial:

$$
\begin{aligned}
\mathbf{V}^{\pi} & =\mathbf{c}^{\pi}+\mathbf{T}_{G^{\mathrm{c}}}^{\pi} \mathbf{V}^{\pi} \\
& =\left(\mathbf{I}-\mathbf{T}_{G^{\mathrm{c}}}^{\pi}\right)^{-1} \cdot \mathbf{c}^{\pi},
\end{aligned}
$$

em que $\mathbf{V}^{\pi}$ é um vetor de tamanho $|S| \times 1$, I é uma matriz identidade de tamanho $|S| \times|S|$, enquanto $\mathbf{c}^{\pi}$ e $\mathbf{T}_{G^{\mathrm{c}}}^{\pi}$ estão descritos a seguir.

\section{Definição 1. (Matrizes de Transição de Política e Vetor de Custo de Política)}

Seja $\pi$ uma política estacionária e cada estado em $S$ seja enumerado como $1,2,3, \ldots,|S|$, $\mathbf{T}^{\pi}$ é uma matriz $|S| \times|S|$, em que cada célula $\left(\mathbf{T}^{\pi}\right)_{i j}$ representa a probabilidade de transição do estado $i$ para o estado $j$ seguindo a política $\pi$, i.e., $\left(\mathbf{T}^{\pi}\right)_{i j}=T(j \mid i, \pi(i))$. A matriz $\mathbf{T}_{G^{c}}^{\pi}$ também é uma matriz $|S| \times|S|$ similar à matriz $\mathbf{T}^{\pi}$, com a diferença que as colunas que representam os estados meta, $s \in S_{g}$, são alteradas para 0, i.e.,

$$
\left(\mathbf{T}_{G^{c}}^{\pi}\right)_{i j}=\left\{\begin{array}{ll}
0 & , \text { se } j \in S_{g} \\
T(j \mid i, \pi(i)) & , \text { nos demais casos, }
\end{array} .\right.
$$

$\mathbf{c}^{\pi}$ é o vetor $|S| \times 1$ em que cada célula $\left(\mathbf{c}^{\pi}\right)_{s}$ representa o custo ao seguir a política $\pi$ no estado s, i.e., $\left(\mathbf{c}^{\pi}\right)_{s}=c(s, \pi(s))$.

Definição 2. (Política própria) Uma política $\pi$ é dita própria se $\lim _{t \rightarrow \infty}\left(\mathbf{T}_{G^{c}}^{\pi}\right)^{t}=\mathbf{0}$, i.e., um estado absorvente em $S_{g}$ é alcançado com probabilidade 1. De maneira equivalente, uma política $\pi$ é uma política própria se o raio espectral ${ }^{1}$ de $\mathbf{T}_{G^{c}}^{\pi}$ for menor que 1 , i.e., $\rho\left(\mathbf{T}_{G^{c}}^{\pi}\right)<1$.

\footnotetext{
1 Mais conhecido pelo termo em inglês spectral radius ou pela função $\rho()$ - letra grega rho.
} 


\subsubsection{Política ótima}

Seja $\Pi$ o conjunto de políticas estacionárias, a função valor ótima $V^{*}(s)=\min _{\pi \in \Pi} V^{\pi}(s)$ é a solução da equação de Bellman:

$$
V^{*}(s)= \begin{cases}0 & , \text { se } s \in S_{g} \\ \min _{a \in A}\left[c(s, a)+\sum_{s^{\prime} \in \mathcal{S}} T\left(s^{\prime} \mid s, a\right) V^{*}\left(s^{\prime}\right)\right] & , \text { nos demais casos. }\end{cases}
$$

A política ótima pode ser obtida com base na função valor ótima por:

$$
\pi^{*}(s)= \begin{cases}\forall a \in A & , \text { se } s \in S_{g} \\ \arg \min _{a \in A}\left[c(s, a)+\sum_{s^{\prime} \in S} T\left(s^{\prime} \mid s, a\right) V^{*}\left(s^{\prime}\right)\right] & , \text { nos demais casos. }\end{cases}
$$

\subsubsection{Algoritmo de Iteração de Política}

O algoritmo de Iteração de Política (Policy Iteration - PI) (Algoritmo 1) é um dos algoritmos clássicos para encontrar uma política ótima $\pi^{*}$ (PUTERMAN, 1994) . Trata-se de um algoritmo iterativo que inicia com uma política inicial própria $\pi_{0}$. Em cada iteração $i$ dois passos são executados: avaliação de política e melhora de política. O passo avaliação de política utiliza a Equação 4 para calcular o valor de $V^{\pi_{i}}(\cdot)$ e o passo melhora de política melhora $\pi_{i}$ obtendo $\pi_{i+1}$.

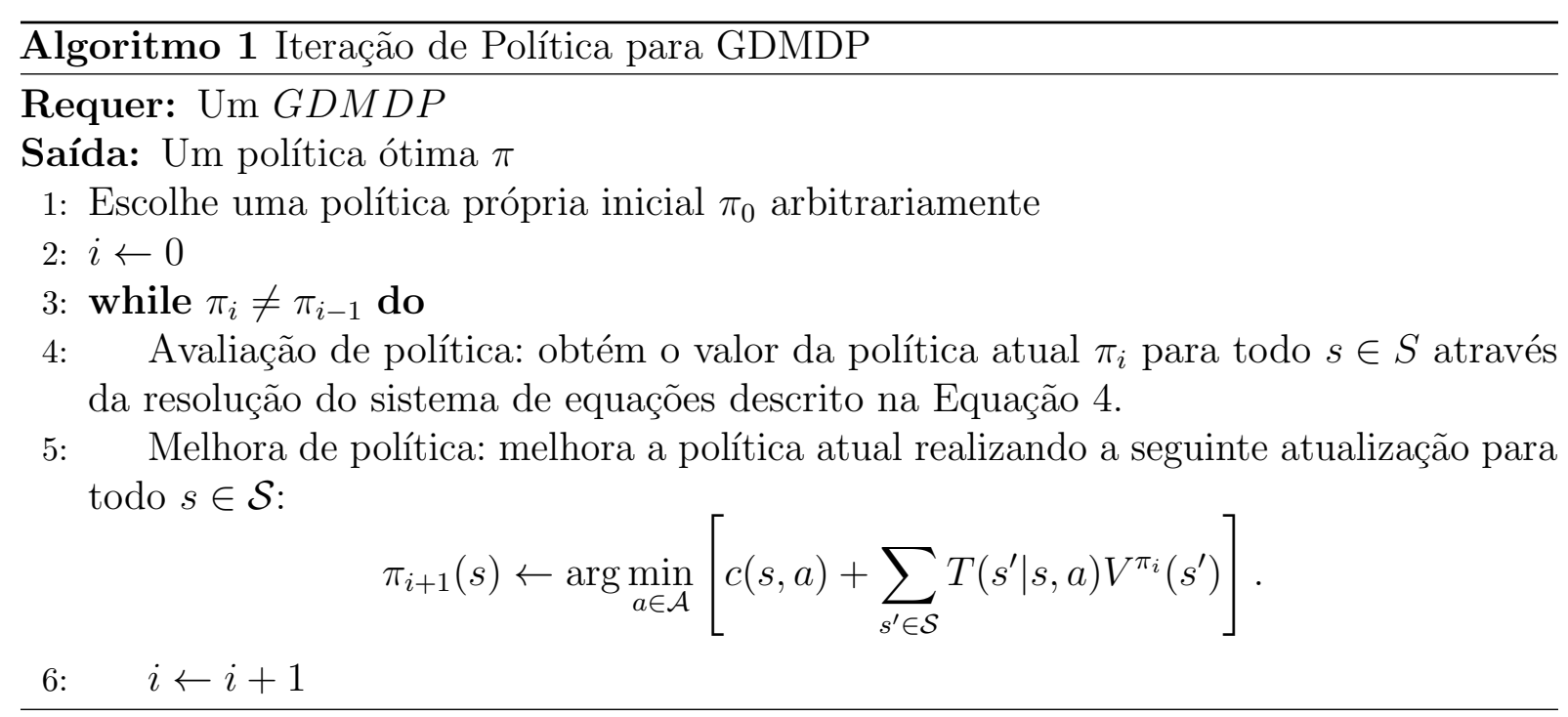

Se $\pi_{0}$ for uma política própria, o algoritmo PI encontra uma política ótima (BERTSEKAS; TSITSIKLIS, 1991). 


\subsubsection{Algoritmo de Iteração de Valor}

O algoritmo de Iteração de Valor (Value Iteration - VI) (Algoritmo 2), assim como o Algoritmo de Iteração de Política, faz parte dos algoritmos clássicos de MDP. Enquanto o algoritmo de Iteração de Política faz uma busca no espaço de políticas, o algoritmo de Iteração de Valor faz uma busca no espaço de valores.

Neste algoritmo, seleciona-se arbitrariamente um valor $V_{0}(s)$ e, em cada iteração $i$ é calculado o valor da função $V_{i}(s)$ baseado no valor da iteração anterior $V_{i-1}(s)$ para cada estado $s \in S$ do MDP. Neste algoritmo, o critério de parada é considerar o resíduo $\max _{s \in \mathcal{S}}\left|V_{i}(s)-V_{i-1}(s)\right|$ e iterar enquanto o resíduo for maior que um erro mínimo desejado $\epsilon$.

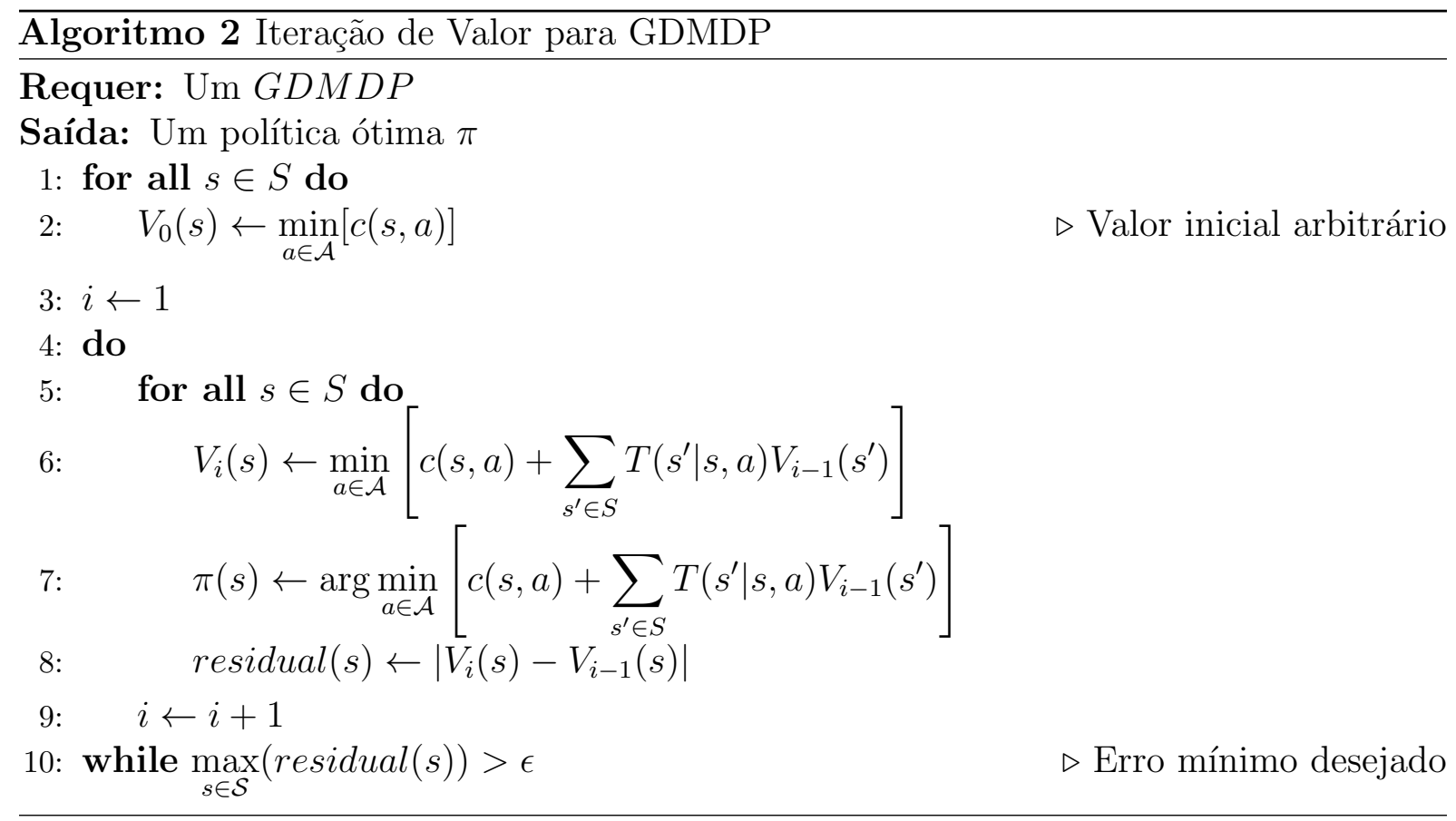

Esse algoritmo encontra uma solução se existir pelo menos uma política ótima (BERTSEKAS; TSITSIKLIS, 1991).

\subsubsection{Algoritmo ILAO*}

Os algoritmos LAO* (HANSEN; ZILBERSTEIN, 1998) e ILAO* (HANSEN; ZILBERSTEIN, 2001) são evoluções dos clássicos algoritmos A* e AO* (NILSSON, 1980). A principal contribuição desses algoritmos é a capacidade de processar grafos cíclicos, e desta forma passaram a ser adotados também na resolução de GDMDPs clássicos. 
Assim como toda a família de algoritmos $A^{*}$, os algoritmos planejam o caminho a partir de um estado inicial $s_{0}$ em direção a um estado meta $s_{g}$. Ao final do processo, um grafo explícito $G^{\prime}$ iniciado pelo estado inicial é expandido até encontrar um estado folha terminal. O grafo explícito $G^{\prime}$ é um sub grafo do grafo original e inclui todos os estados alcançáveis ao aplicar a política partindo do estado inicial e que permite chegar até o estado final.

O algoritmo LAO* calcula o valor dos nós do grafo explícito usando iteração de valor, isso permite que o grafo possa ser calculado mesmo que não exista uma ordem topológica, permitindo assim obter respostas em grafos que contém laços. O algoritmo LAO* consiste em 2 passos: (i) expansão do grafo; e (ii) revisão, em que os valores são atualizados. A diferença entre LAO* e ILAO* é que o último integra o passo de revisão dentro do passo de expansão.

\subsection{Atitudes em relação ao risco}

Uma vez que $C^{\pi}$ é uma variável aleatória podem ser definidas três atitudes em relação ao risco (KEENEY; RAIFFA, 1976): neutro, propenso e averso. Mas primeiro, precisamos definir a equivalente de certeza de uma política $\pi$.

Intuitivamente, o equivalente de certeza é um custo garantido que o agente preferiria pagar, em vez de arriscar por ter um custo menor, mas incerto. Se $V^{\pi}(s)<\infty$ e existe a função inversa $u^{-1}(\mathbb{R}) \rightarrow \mathbb{R}^{+}$, o equivalente de certeza $\bar{C}^{\pi}(s)$ de uma política $\pi$ é definido por:

$$
\bar{C}^{\pi}(s)=u^{-1}\left(V^{\pi}(s)\right),
$$

e o custo esperado $\widetilde{C}^{\pi}(s)$ de uma política $\pi$ é definido por:

$$
\widetilde{C}^{\pi}(s)=\mathrm{E}\left[C^{\pi} \mid s_{0}=s\right] .
$$

Um agente é propenso a risco se $\bar{C}^{\pi}(s)<\widetilde{C}^{\pi}(s)$, averso a risco se $\bar{C}^{\pi}(s)>\widetilde{C}^{\pi}(s)$ e neutro a risco se $\bar{C}^{\pi}(s)=\widetilde{C}^{\pi}(s)$ para todo estado $s \in \mathcal{S}$ e política $\pi \in \Pi$. Por exemplo, um agente averso ao risco prefere pagar com certeza um custo de $\bar{C}^{\pi}(s)$, mesmo se houver um custo médio esperado menor usando uma outra política. 
Considerando essas definições, o GDRSMDP que considera a função utilidade identidade (descrito na Seção 2.1) caracteriza uma atitude neutra a risco.

\subsection{MDP Sensivel a Risco e Dirigido a Meta}

Com base na Teoria da Utilidade Esperada (BERNOULLI, 1954), em (HOWARD; MATHESON, 1972) é proposta a função utilidade exponencial para modelar atitude ao risco do agente. A função utilidade apresenta algumas propriedades interessantes: ( $i$ ) considera-se um parâmetro arbitrário $\beta$ que modela a atitude ao risco do agente; e (ii) é possível construir uma equação de otimalidade, que é o caminho para definição dos algoritmos de Iteração de Valor e Iteração de Política.

Formalmente um MDP sensível a risco e dirigido a meta (Goal-Directed Risk Sensitive Markov Decision Process - GDRSMDP) é definido por uma tupla GDRSMDP= $(G D M D P, \beta)$, em que:

- $G D M D P$ é um MDP dirigido à meta.

- $\beta$ é o fator de sensibilidade a risco.

Em GDRSMDPs, a função valor da política $\pi$ é definida por:

$$
V^{\pi}(s)=\lim _{M \rightarrow \infty} \mathrm{E}\left[\operatorname{sgn}(\beta) \exp \left(\beta \sum_{t=0}^{M} c\left(s_{t}, \pi\left(s_{t}\right)\right)\right) \mid \pi, s_{0}=s\right],
$$

em que E representa a esperança quando a política $\pi$ é executada, $\exp ()$ é a função exponencial e o agente é averso ao risco se $\beta>0$, propenso ao risco se $\beta<0$ e neutro ao risco se $\beta \rightarrow 0$. O valor da política $\pi$ para o estado $s$ pode ser obtido resolvendo o seguinte sistema de equações:

$$
V^{\pi}(s)= \begin{cases}\operatorname{sgn}(\beta) & , \text { se } s \in S_{g} \\ \exp (\beta c(s, \pi(s))) \sum_{s^{\prime} \in \mathcal{S}} T\left(s^{\prime} \mid s, \pi(s)\right) V^{\pi}\left(s^{\prime}\right) & , \text { nos demais casos }\end{cases}
$$

ou em sua forma matricial:

$$
\begin{aligned}
\mathbf{V}^{\pi} & =\left(\mathbf{D}^{\pi}\right)^{\beta}\left(\mathbf{T}_{G^{\mathrm{c}}}^{\pi} \mathbf{V}^{\pi}-\operatorname{sgn}(\beta)\left(\mathbf{1}-\mathbf{T}_{G^{\mathrm{c}}}^{\pi} \mathbf{1}\right)\right) \\
& =\left(\left(\mathbf{D}^{\pi}\right)^{\beta} \mathbf{T}_{G^{\mathrm{c}}}^{\pi}-\mathbf{I}\right)^{-1} \cdot\left(\mathbf{D}^{\pi}\right)^{\beta} \cdot \operatorname{sgn}(\beta)\left(\mathbf{1}-\mathbf{T}_{G^{\mathrm{c}}}^{\pi} \mathbf{1}\right),
\end{aligned}
$$

em que $\mathbf{V}^{\pi}$ é um vetor de tamanho $|S| \times 1$, I é uma matriz identidade de tamanho $|S| \times|S|$, 1 é um vetor-coluna apenas com o valor 1 e $\mathbf{D}^{\pi}$ é uma matriz diagonal $|S| \times|S|$ com os elementos de $\exp \left(\mathbf{c}^{\pi}\right)$. A definição das matrizes $\mathbf{c}^{\pi}$ e $\mathbf{T}_{G^{c}}^{\pi}$ estão na Definição 1. 
Definição 3. (política $\beta$-factivel) (PATEK, 2001) Uma política $\pi$ é $\beta$-factível se a probabilidade de não estar em um estado absorvente desaparece mais rápido do que o custo acumulado exponencial, i.e., $\lim _{t \rightarrow \infty}\left(\left(\mathbf{D}^{\pi}\right)^{\beta} \mathbf{T}_{G^{c}}^{\pi}\right)^{t}=\mathbf{0}$. De forma equivalente, uma política $\pi$ é $\beta$-factivel se o raio espectral de $\left(\mathbf{D}^{\pi}\right)^{\beta} \mathbf{T}_{G^{c}}^{\pi}$ for menor que 1, i.e., $\rho\left(\left(\mathbf{D}^{\pi}\right)^{\beta} \mathbf{T}_{G^{c}}^{\pi}\right)<1$.

Seja $\Pi$ o conjunto de políticas estacionárias, a função valor ótima $V^{*}(s)=$ $\min _{\pi \in \Pi} V^{\pi}(s)$ é a solução da seguinte equação:

$$
V^{*}(s)= \begin{cases}\operatorname{sgn}(\beta) & , \text { se } s \in S_{g} \\ \min _{a \in A}\left[\exp (\beta c(s, a)) \sum_{s^{\prime} \in S} T\left(s^{\prime} \mid s, a\right) V^{*}\left(s^{\prime}\right)\right] & , \text { nos demais casos }\end{cases}
$$

e a política ótima pode ser obtida com base na função valor ótima por:

$$
\pi^{*}(s)=\arg \min _{a \in A}\left[\exp (\beta c(s, a)) \sum_{s^{\prime} \in S} T\left(s^{\prime} \mid s, a\right) V^{*}\left(s^{\prime}\right)\right] .
$$

\subsubsection{Algoritmo de Iteração de Política Sensível a Risco}

Supondo que exista uma política inicial $\pi_{0} \beta$-factível, o algoritmo de Iteração de Política Sensível a Risco (Algoritmo 3) permite encontrar uma política ótima $\pi^{*}$ (PATEK, 2001). Em que a cada iteração $i$ dois passos são executados: avaliação de política e melhora de política. O passo avaliação de política utiliza a Equação 12 para calcular o valor de $V^{\pi_{i}}(\cdot)$ e o passo de melhoria de política, melhora $\pi_{i}$ obtendo $\pi_{i+1}$.

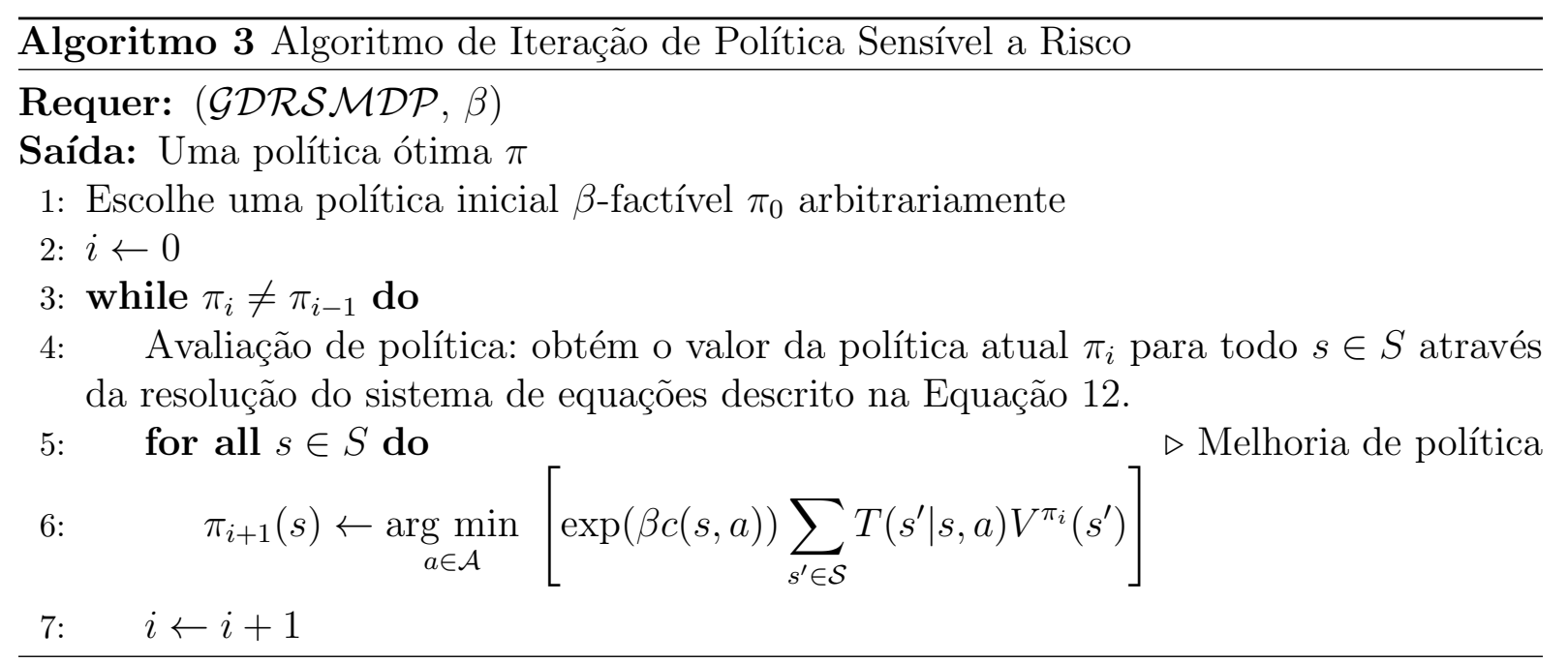

Quando $\beta<0$ (propenso a risco) e a política $\pi$ é própria, então $\pi$ também é $\beta$-factível. Entretanto, não há garantia para toda política quando $\beta>0$ (averso a risco). 
Dado um GDRSMDP, apenas o trabalho (FREIRE; DELGADO, 2016) demonstra como obter o valor de $\beta>0$ que resulte em uma política $\beta$-factível o mais aversa a risco.

\subsubsection{Algoritmo de Iteração de Valor Sensível a Risco}

Apesar de não ter sido explicitamente definido no artigo de Patek (2001), é possível definir um algoritmo de Iteração de Valor Sensível a Risco em que em cada iteração $i$ é calculado o valor $V^{i}(s)$ baseado no valor $V^{i-1}(s)$ para cada estado $s \in S$, isto é:

$$
V^{i}(s)=\min _{a \in A}\left[Q^{i}(s, a)\right]
$$

em que:

$$
Q^{i}(s, a)=\exp (\beta c(s, a)) \sum_{s^{\prime} \in S} T\left(s^{\prime} \mid s, a\right) V^{i-1}\left(s^{\prime}\right) .
$$

Um possível critério de parada é considerar o resíduo $\max _{s \in S}\left|V_{i}(s)-V_{i-1}(s)\right|$ e iterar enquanto o resíduo for maior que um erro mínimo desejado $\epsilon$. Esse algoritmo encontra uma solução se existir pelo menos uma política $\pi_{0} \beta$-factível. 


\section{ILAO* Sensível a Risco}

O algoritmo de Iteração de Política e de Iteração de Valor Sensíveis a Risco precisam atualizar o conjunto completo de estados em cada iteração, por esse motivo são muito custosos quando o problema tem muitos estados. Uma outra limitação do algoritmo

Iteração de Política Sensível a Risco é a necessidade de ter uma política inicial $\pi^{0} \beta$-factível para garantir a convergência do algoritmo.

Por outro lado para resolver MDPs dirigidos a meta clássicos, existe o algoritmo heurístico ILAO* (HANSEN; ZILBERSTEIN, 2001), um algoritmo eficiente que atualiza apenas o subconjunto de estados que são relevantes para o problema considerando que é conhecido o estado inicial $s_{0}$ a partir do qual desejamos chegar no estado meta. Esse algoritmo permite reduzir o número de vezes que um estado é avaliado e permite encontrar uma política parcial ótima. Neste trabalho é proposto uma adaptação desse algoritmo que é chamada de ILAO* Sensível a Risco (Risk Sensitive ILAO* - RS-ILAO*).

A ideia principal do algoritmo RS-ILAO* é expandir e atualizar os estados alcançáveis, seguindo a política gulosa atual (i.e., a melhor política até o momento) e criando um grafo explícito $G^{\prime}$ o qual contém todos os estados visitados até então e todas as ações aplicáveis nesses estados, bem como os estados sucessores correspondentes. No grafo explícito $G^{\prime}$, cada nó representa um estado $s \in S$ e cada aresta representa uma ação $a \in A$. Nesse grafo, um estado folha (aquele que não tem sucessores descobertos) é uma folha terminal se é um estado meta, caso contrário é um estado não terminal.

O algoritmo RS-ILAO* consiste em dois passos: (i) busca em profundidade em que são feitas a expansão da melhor solução parcial, a atualização dos custos e a identificação das melhores ações criando um grafo da melhor solução parcial chamado de $G^{\prime \prime}$; e (ii) teste de convergência que chama o algoritmo de Iteração de Valor Sensível a Risco para todos os estados de $G^{\prime \prime}$ e verifica se o grafo da melhor solução mudou. Caso exista mudança no grafo, o algoritmo continua, caso contrário, foi encontrada a solução.

O algoritmo RS-ILAO* (Algoritmo 4) recebe como entrada um GDRSMDP e o estado inicial $s_{0}$; e devolve como saída uma política parcial ótima. Nas Linhas 3 e 4 do Algoritmo 4, o grafo explícito $G^{\prime}$ é inicializado apenas com o estado inicial. As Linhas 6 a 11 do Algoritmo 4 são executadas enquanto o teste de convergência da Linha 11 não devolva verdadeiro. Esse teste de convergência é feito primeiro chamando o algoritmo de 
Iteração de Valor Sensível a Risco com o grafo $G^{\prime}$ (note que as atualizações são feitas no grafo da melhor solução $G^{\prime \prime}$ ) e caso haja mudança em $G^{\prime \prime}$ de modo que apareça alguma folha não esperada em $G^{\prime \prime}$, o algoritmo continua.

Se o algoritmo ainda não convergiu, é realizada uma busca em profundidade a partir do estado inicial $s_{0}$ enquanto o grafo explícito tiver alguma folha não terminal (Algoritmo 4, Linhas 7-10). Durante a busca em profundidade o valor dos estados expandidos e seus ancestrais são atualizados apenas uma vez e a melhor ação é identificada atualizando o grafo $G^{\prime \prime}$. Note que os estados marcados como visitados pela busca em profundidade devem ser atualizados para não visitados antes de fazer uma nova busca em profundidade (Algoritmo 4, Linhas 9-10).

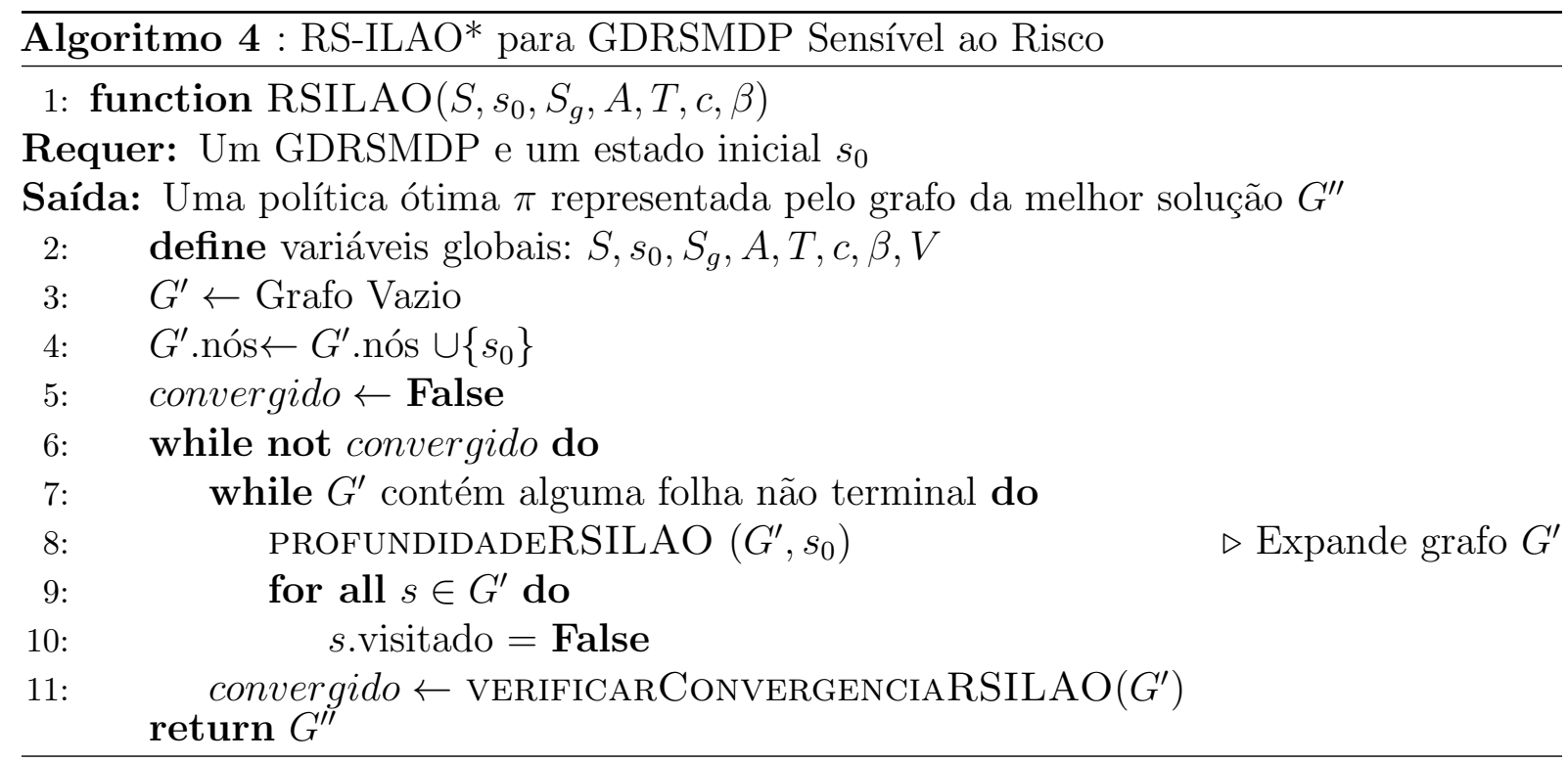

O algoritmo PROFUNDIDADERSILAO (Algoritmo 5), que é chamado na Linha 8 do Algoritmo 4, é responsável tanto pela expansão dos nós do grafo explícito $G^{\prime}$ quanto pela atualização (revisão) dos custos calculados para os estados do grafo $G^{\prime}$. A expansão não ocorre indiscriminadamente, ela ocorre usando a melhor solução parcial. O grafo da melhor solução parcial é um subgrafo do grafo explícito que inclui os nós e arestas que melhor atendem o critério de otimização. Neste algoritmo, se o estado $s$ já foi expandido, todos os sucessores $s^{\prime}$ do estado $s$ considerando a melhor solução parcial não visitados são expandidos de forma recursiva (Algoritmo 5, Linhas 3-6). Caso contrário, o estado $s$ é expandido (Algoritmo 5, Linhas 7-8). Durante a busca em profundidade, o valor do estado $s$ é atualizado (Algoritmo 5, Linha 9) e a melhor ação para o estado $s$ no grafo explícito é 
marcada (Algoritmo 5, Linha 10). Note que esses estados e as melhores ações marcadas durante essa busca farão parte do grafo da melhor solução parcial $G^{\prime \prime}$.

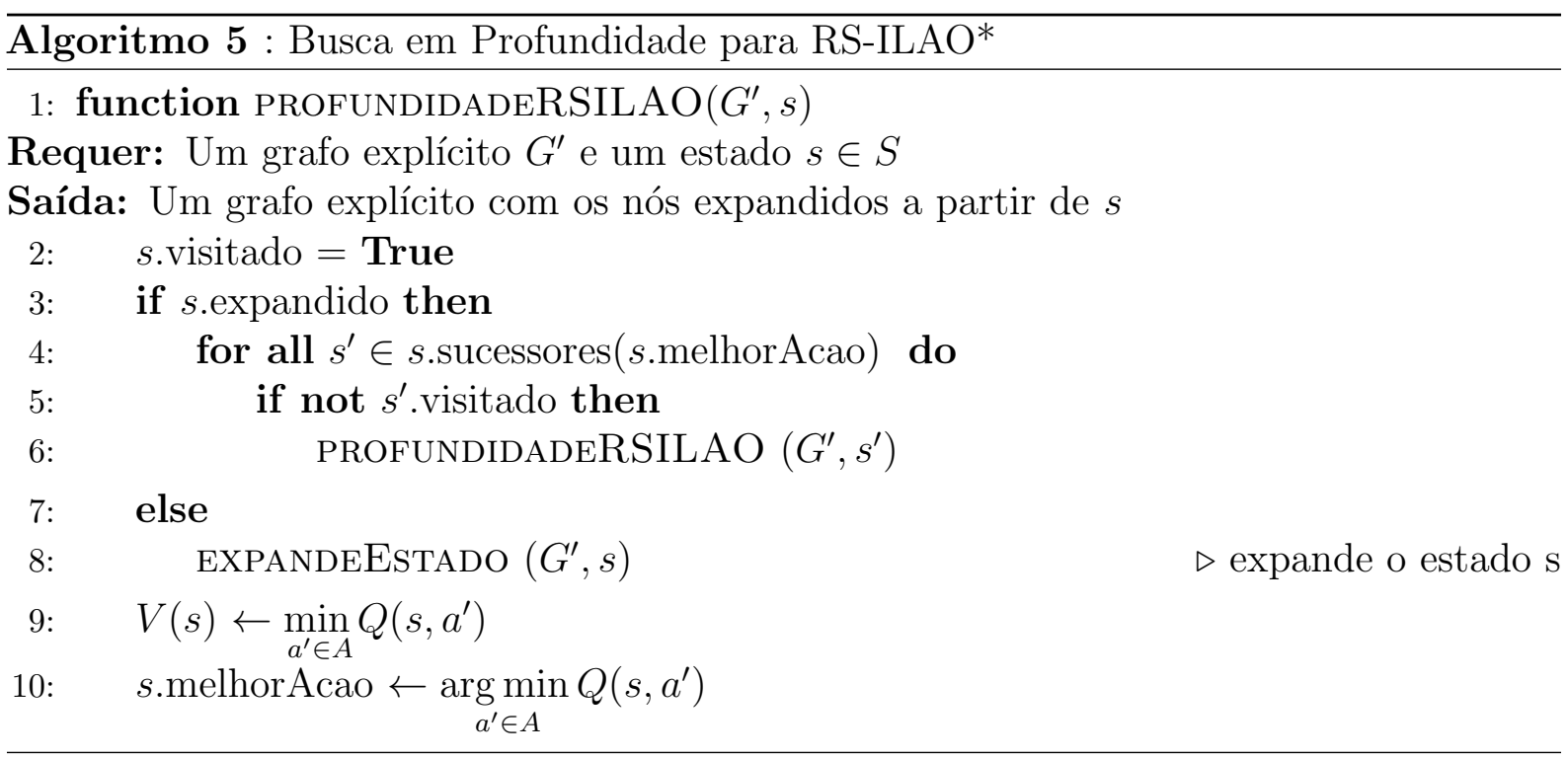

O algoritmo VERIFICARCONVERGENCIARSILAO (Algoritmo 6), que é chamado na Linha 11 do Algoritmo 4, é responsável por avaliar a convergência e atualizar todos os estados pertencentes ao grafo $G^{\prime \prime}$. Na Linha 4, o algoritmo define o grafo da melhor solução parcial $G^{\prime \prime}$ como o subgrafo de $G$ que inclui os estados e as melhores ações marcadas durante a busca em profundidade. O algoritmo VERIFICARCONVERGENCIARSILAO executa o algoritmo de Iteração de Valor Sensível a Risco no grafo $G^{\prime \prime}$, atualizando todos os estados de $G^{\prime \prime}$ enquanto o resíduo seja maior que o máximo erro desejado $\epsilon$ (Algoritmo 6, Linha 5-13). Se durante as iterações, algum estado folha em $G^{\prime \prime}$ for identificado como ainda não expandido, o algoritmo devolve falso, isto é não convergiu (Algoritmo 6, Linha 10-11).

O algoritmo Q (Algoritmo 7), que é chamado pelos Algoritmos 5 e 6, é responsável pelo cálculo do valor $Q$ para um par estado-ação utilizando a função exponencial. O algoritmo ExPANDEEstados (Algoritmo 8), que é chamado pelo Algoritmo 5, é responsável por encontrar os sucessores do estado $s$ e inicializar o valor desses estados com a heurística $h$. 


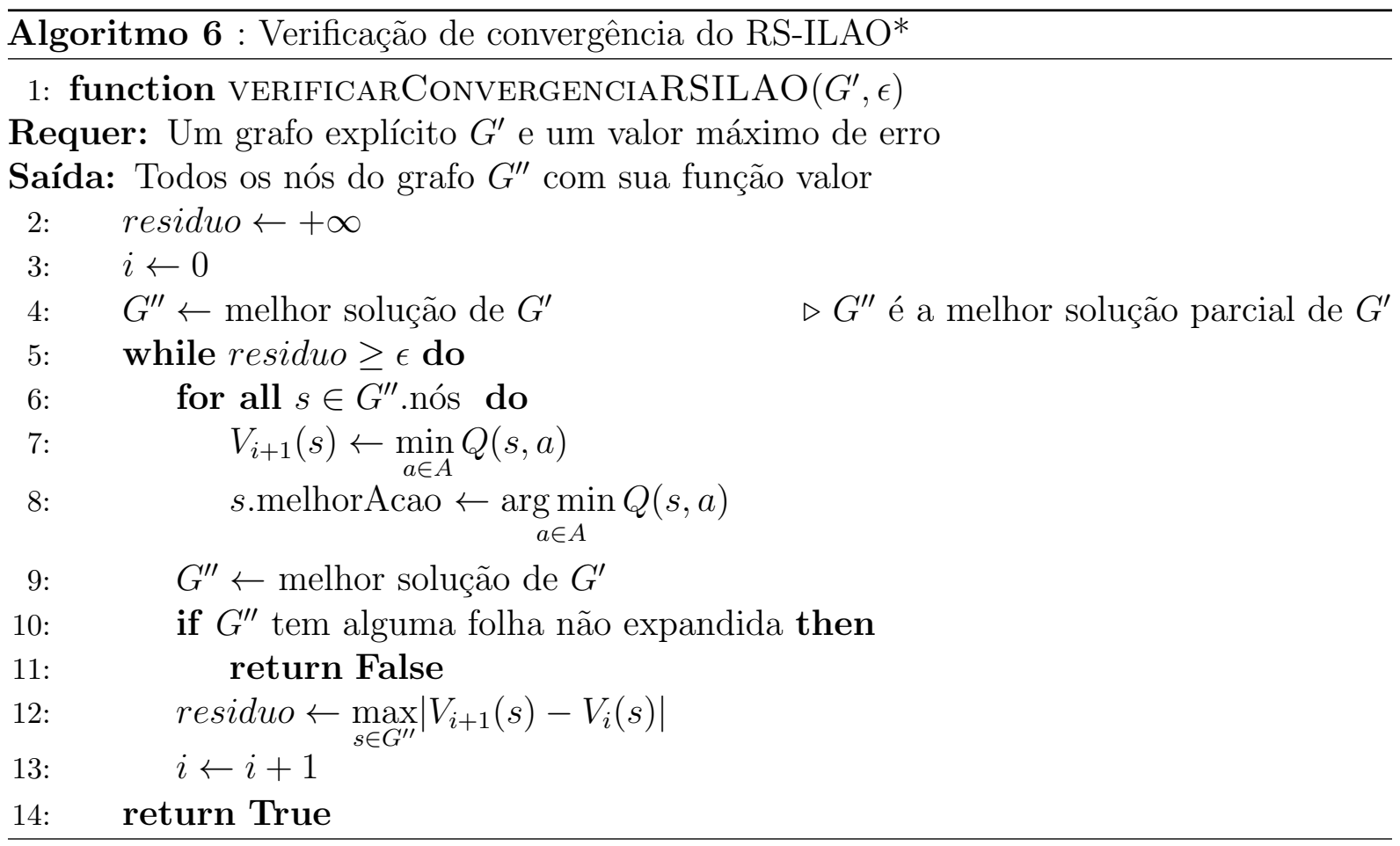

Algoritmo 7 : Função utilidade exponencial para RS-ILAO*

1: function $\mathrm{Q}(s, a)$

Requer: Um GDRSMDP, o fator de risco $\beta$, um estado $s \in S$ e uma ação $a \in A$.

Saída: O custo estimado do estado $s$ caso seja executada a ação $a$

2: $\quad$ return $\exp (\beta c(s, a)) \sum_{s^{\prime} \in S} T\left(s^{\prime} \mid s, a\right) V\left(s^{\prime}\right)$

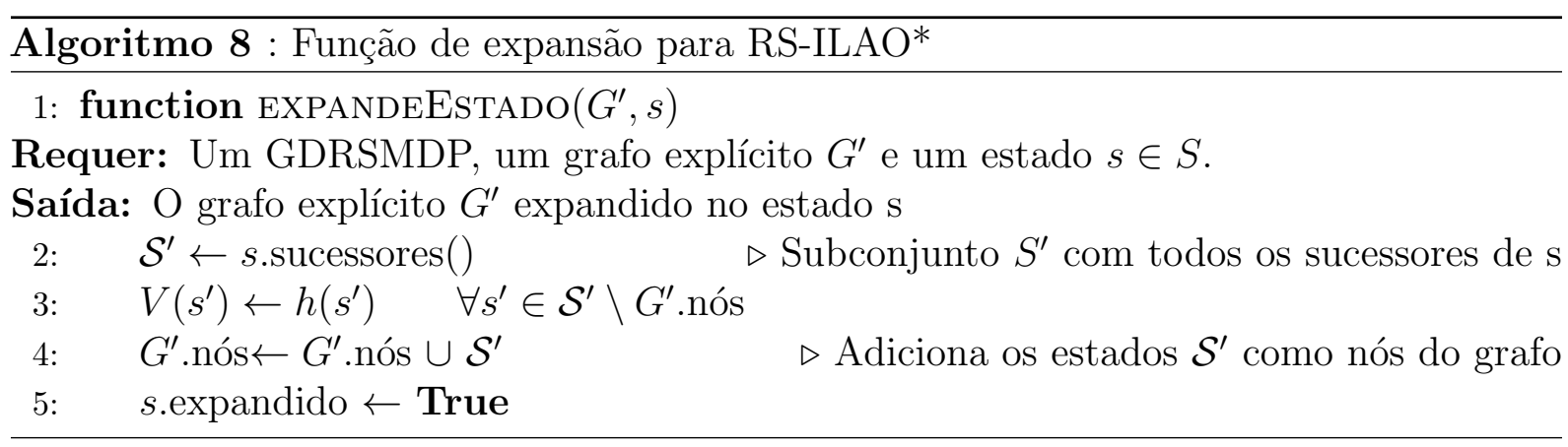




\subsection{Convergência}

A prova de convergência do algoritmo RS-ILAO* segue da prova de convergência do algoritmo LAO* (HANSEN; ZILBERSTEIN, 2001), porém a prova deve considerar a função de atualização de GDRSMDPs.

Proposição 1. Se a heurística $h(s)$ da função valor é usada no algoritmo $R S-I L A O^{*}$ é admissivel, a admissibilidade da função valor é mantida durante a execução do algoritmo $R S$-ILAO*, isto é, se $h(s) \leq V^{*}(s), \forall s \in S$ então $V(s) \leq V^{*}(s), \forall s \in S$ em qualquer ponto do algoritmo.

Teorema 1. Se a heurística $h(s)$ da função valor é admissível e o algoritmo de Iteração de Valor Sensível a Risco é usado no passo de verificação de convergência no algoritmo $R S$-ILAO*, a função valor $V(s)$ converge a menos de um $\epsilon$ para $V^{*}(s)$ para todo estado $s$ que pertence ao grafo da melhor solução após um número finito de iterações.

\subsection{Funções heurísticas}

Entre as heurísticas admissíveis para inicializar a função valor no algoritmo RSILAO* estão:

- Heurística 1: $h_{1}(s)=\operatorname{sgn}(\beta), \forall s \in S$.

Esta heurística utiliza o sinal de $\beta$ para todos os estados.

- Heurística de custo imediato:

$$
h_{2}(s)= \begin{cases}\operatorname{sgn}(\beta) & , \text { se } s \in S_{g} \\ \operatorname{sgn}(\beta) \times e^{\beta \min C(s, a)} & , \text { nos demais casos. }\end{cases}
$$

Esta heurística utiliza a função exponencial considerando o menor custo imediato de cada estado e o fator de risco se o estado não é meta. Caso contrário, utilizada a constante 1 .

- Heurística de Manhattan:

$$
h_{3}(s)= \begin{cases}\operatorname{sgn}(\beta) & , \text { se } s \in S_{g} \\ \operatorname{sgn}(\beta) \times e^{\beta \text { manhattan }} & , \text { nos demais casos. }\end{cases}
$$


Esta heurística utiliza a função exponencial considerando o caminho de Manhattan para cada estado e o fator de risco se o estado não é meta. Caso contrário utilizada a constante 1 .

\subsection{Exemplo de execução do algoritmo $R S-I L A O^{*}$}

Nesta seção é apresentada a aplicação do algoritmo RS-ILAO* no Problema 1 de Travessia do Rio com um grid de tamanho $3 \times 3$. Nesse exemplo temos 9 estados $S=$ $\{1,2,3,4,5,6,7,8,9\}$. A Figura 2 apresenta todos os estados e as possíveis movimentações através das setas. Neste exemplo, o estado inicial é $s_{0}=1$ e o estado meta é $s_{g}=3$. Foi utilizada a heurística $h_{2}$ e o fator de risco $\beta=0,10$.

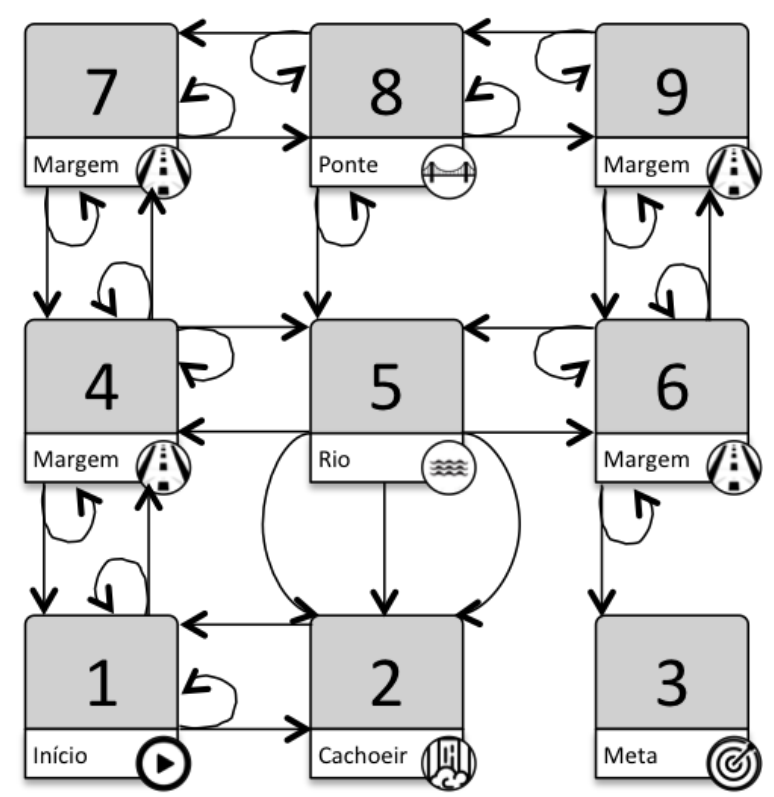

Figura 2 - Estados e transições no Problema 1 de Travessia do Rio em um grid de tamanho $3 \times 3$.

Fonte: Elthon Manhas de Freitas, 2018

A Figura 3 apresenta os principais passos da aplicação do algoritmo RS-ILAO* nesse exemplo. Na parte inferior de cada estado $s$ há o valor atual da função valor $V(s)$. Todos os estados que aparecem em cada figura fazem parte do grafo explícito $G^{\prime}$. As linhas contínuas representam o grafo da melhor solução parcial $G^{\prime \prime}$ e as linhas tracejadas representam o resto do grafo explícito.

A Figura 3(a) mostra o nó raiz do grafo explícito $G^{\prime}$ que corresponde ao estado inicial 1 e cujo valor é inicializado com o valor da heurística $h_{2}(s)=e^{\beta \min C(s, a)}=1,4918$. 
A Figura 3(b) mostra o resultado de aplicar a busca em profundidade no grafo da melhor solução parcial, que inclui apenas o estado 1. Esse estado é expandido e assim são incluídos seus sucessores (estado 4 e estado 2) no grafo explícito $G^{\prime}$. O valor desses dois estados é iniciado com o valor $h_{2}(s)$, o valor do estado 1 é atualizado e a melhor ação para esse estado é marcada. Como $G^{\prime}$ contém uma folha não terminal o algoritmo continua.

A Figura 3(c) mostra o resultado de aplicar uma nova busca em profundidade no grafo da melhor solução parcial, que agora inclui os estados 1 e 2. O estado 2 é expandido, o valor é atualizado e a melhor ação é marcada, após isso o valor do estado 1 é atualizado e a melhor ação para ele também é marcada. Como $G^{\prime}$ contém uma folha não terminal o algoritmo continua.

A Figura 3(d) mostra o resultado de aplicar uma nova busca em profundidade no grafo da melhor solução parcial, que agora inclui os estados 1 e 4 . O estado 4 é expandido e assim os estados 5 e 7 são incluídos no grafo explícito e inicializados com a heurística. Os valores dos estados 4 e 1 são atualizados e a melhor ação é marcada para cada um deles. Como $G^{\prime}$ contém uma folha não terminal o algoritmo continua.

A Figura 3(e) mostra o resultado de aplicar uma busca em profundidade no grafo da melhor solução parcial que inclui os estados 1, 4 e 5. O estado 5 é expandido e assim o estado 6 é incluído no grafo explícito e inicializado com a heurística. Os valores dos estados 5, 4 e 1 são atualizados e a melhor ação é marcada para cada um deles.

Por fim, a Figura 3(f) mostra o resultado final, i.e. o grafo da melhor solução final $G^{\prime \prime}$, após aplicar o algoritmo de Iteração de Valor Sensível a Risco. 


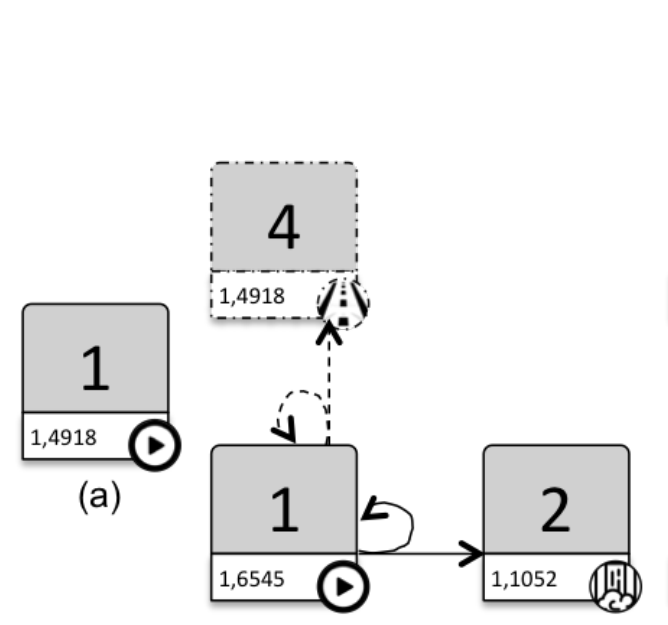

(b)

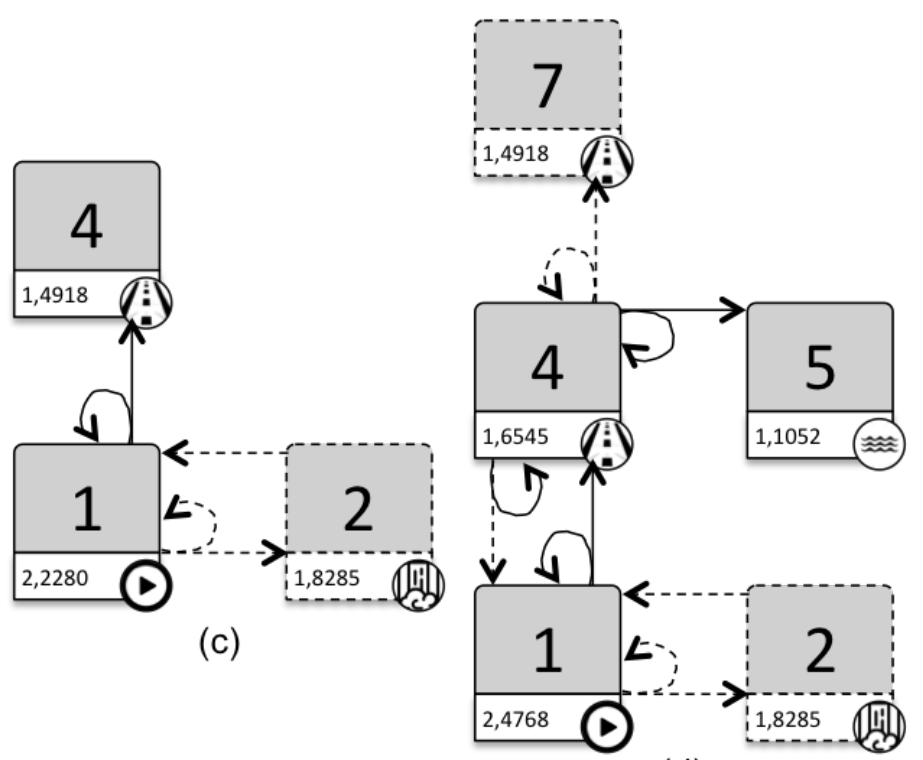

(d)

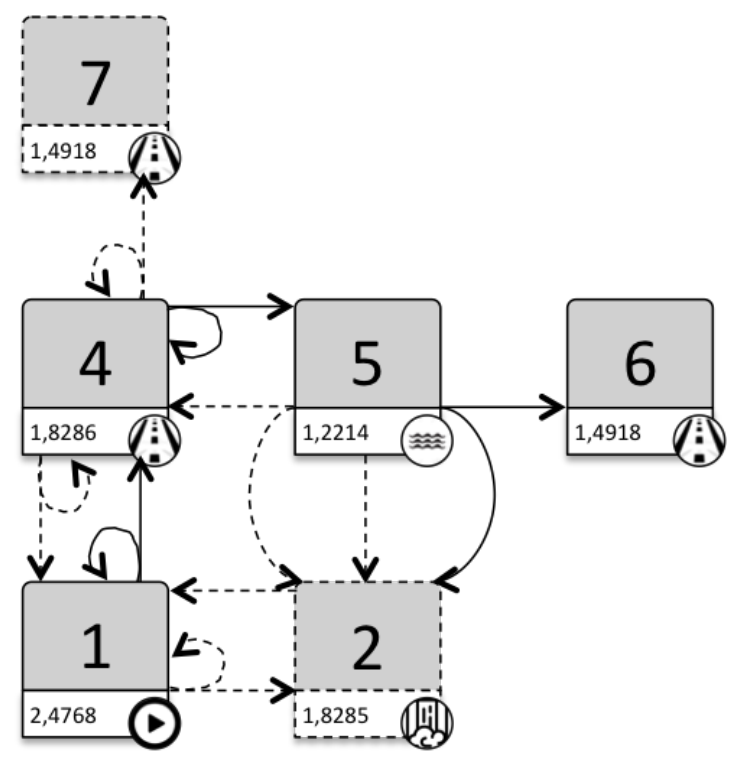

(e)

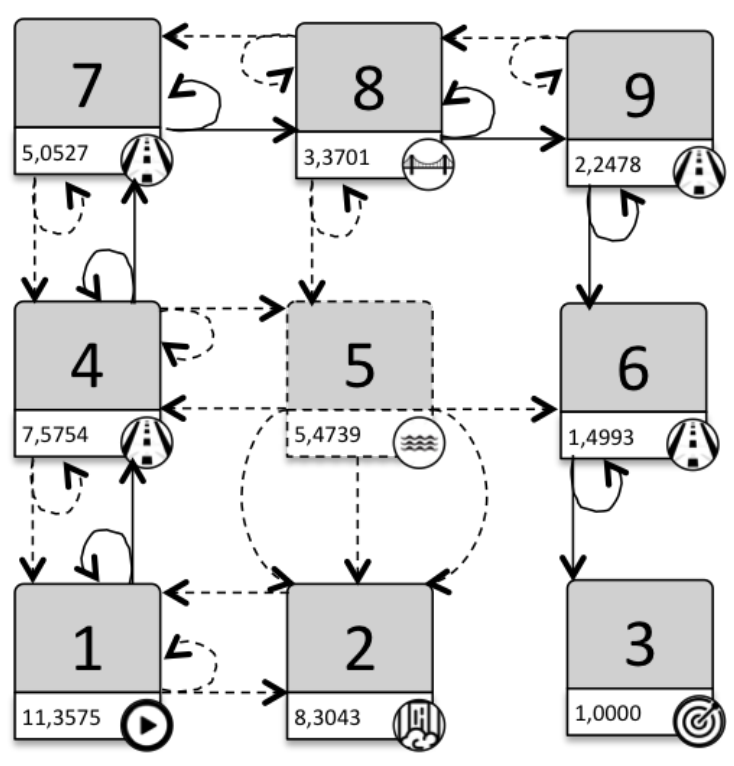

(f)

Figura 3 - Principais passos do algoritmo RS-ILAO* para um domínio da Travessia do Rio com um grid de tamanho $3 \times 3$

Fonte: Elthon Manhas de Freitas, 2018 


\section{Estratégia LogSumExp para GDRSMDP}

Apesar de modelar risco, soluções que implementam a função utilidade exponencial em processos de decisão markovianos não são muito usadas na literatura se comparadas a outros tipos de função utilidade conforme identificado no trabalho de Freitas, Delgado e Freire (2017). Um dos principais limitadores é o alto valor numérico resultante da função valor $V^{\pi}$. Dependendo dos parâmetros do problema - entre os parâmetros está o número de estados - os expoentes resultantes podem se tornar tão grandes que não podem ser processados usando uma variável de ponto flutuante de 64 bits $^{1}$. Mesmo quando o cálculo dos valores intermediários são suportados, a variação de expoentes pode provocar erros de precisão ocasionados por valores desprezados em operações matemáticas de números com expoentes muito distintos (GOLDBERG, 1991).

Este tipo de problema, vem se tornando mais comum em algoritmos de aprendizado de máquina (ROBERT, 2014). Uma das técnicas que vem sendo usada para lidar com este tipo de problema é através de uma aproximação chamada de estratégia LogSumExp - LSE. Esta técnica foi inicialmente proposta por Naylor, Donelly e Sha (2001) e vem sendo usada, com sucesso, em diversos trabalhos recentes (NIELSEN; SUN, 2016; CHEN; GAO, 2016).

A função utilidade exponencial descrita pela Equação 11, modela as atitudes em relação ao risco, mas a pergunta que fazemos é: seria possível utilizar a estratégia LogSumExp e ainda assim manter a atitude em relação ao risco de acordo com a Teoria da Utilidade Esperada definida por Bernoulli (1954) e modelada para MDPs por Howard e Matheson (1972)?

No trabalho de Kahng e Wang (2006), três estratégias de aproximação foram avaliadas e comparadas - LogSumExp (NAYLOR; DONELLY; SHA, 2001), GordianL (SIGL; DOLL; JOHANNES, 1991) e Lp-Norm (KENNINGS; MARKOV, 2000). A estratégia LogSumExp foi escolhida neste trabalho por utilizar uma função logarítmica sobre uma função exponencial, o que transforma um efeito de progressão geométrica em um efeito de progressão aritmética. A Figura 4 apresenta este efeito aplicado sobre os principais fatores da função utilidade: $\mathrm{O}$ fator de risco $\beta$ e a função de custo imediato $c$.

1 Tipo de variável utilizada por diversas linguagens, dentre elas o Java, utilizada nos experimentos deste trabalho. 


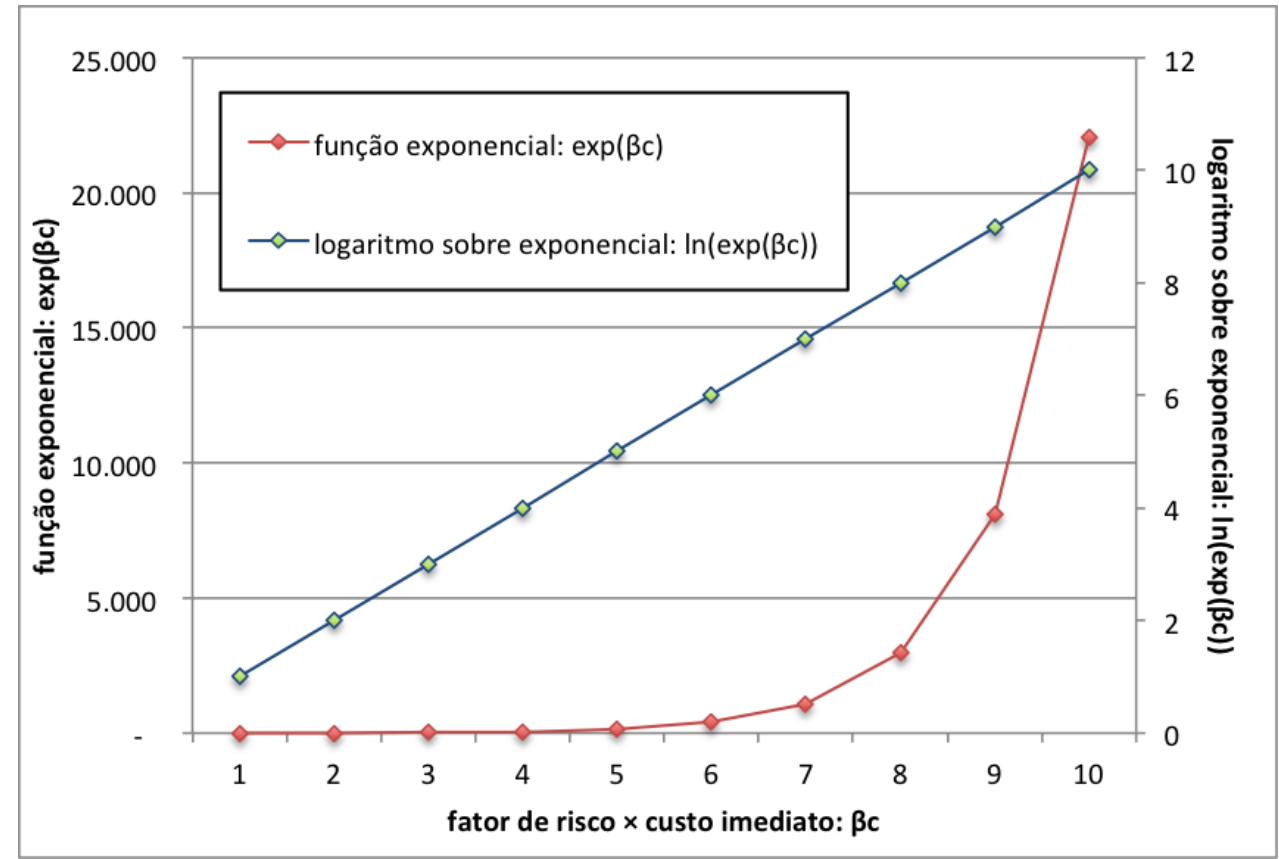

Figura 4 - Análise da função exp sobre a variável risco $\times$ custo imediato $\beta c$ (eixo da esquerda) e da função de logaritmo natural aplicada à função exponencial (eixo da direita)

Fonte: Elthon Manhas de Freitas, 2018

A seguir é mostrado como a função logaritmo natural foi aplicada em todos os fatores da função valor de uma política $\pi$ para GDRSMDPs (Equação 12). Seja a função $L^{\pi}(s)$ definida por:

$$
\begin{aligned}
L^{\pi}(s) & =\frac{1}{\beta} \ln \left[\operatorname{sgn}(\beta) V^{\pi}(s)\right] \\
& = \begin{cases}0 & , \text { se } s \in S_{g} \\
\frac{1}{\beta} \ln \left[\operatorname{sgn}(\beta) \exp (\beta c(s, \pi(s))) \sum_{s^{\prime} \in \mathcal{S}} T\left(s^{\prime} \mid s, \pi(s)\right) \cdot V^{\pi}\left(s^{\prime}\right)\right], & , \text { nos demais casos. }\end{cases}
\end{aligned}
$$

O Sistema de Equações 20 pode ser resolvido da seguinte forma para todo $s \notin S_{g}$ :

$$
\begin{aligned}
L^{\pi}(s) & =\frac{1}{\beta} \ln \left[\exp (\beta c(s, \pi(s))) \sum_{s^{\prime} \in \mathcal{S}} T\left(s^{\prime} \mid s, \pi(s)\right) \cdot \operatorname{sgn}(\beta) V^{\pi}\left(s^{\prime}\right)\right] \\
& =c(s, \pi(s))+\frac{1}{\beta} \ln \left[\sum_{s^{\prime} \in \mathcal{S}} T\left(s^{\prime} \mid s, \pi(s)\right) \cdot \operatorname{sgn}(\beta) V^{\pi}\left(s^{\prime}\right)\right] \\
& =c(s, \pi(s))+\frac{1}{\beta} \ln \left[\sum_{s^{\prime} \in \mathcal{S}} \exp \left(\ln \left[T\left(s^{\prime} \mid s, \pi(s)\right)\right]\right) \cdot \exp \left(\ln \left[\operatorname{sgn}(\beta) V^{\pi}\left(s^{\prime}\right)\right]\right)\right] \\
& =c(s, \pi(s))+\frac{1}{\beta} \ln \left[\sum_{s^{\prime} \in \mathcal{S}} \exp \left(\ln \left[T\left(s^{\prime} \mid s, \pi(s)\right)\right]+\beta L^{\pi}(s)\right)\right]
\end{aligned}
$$


Uma vez que a estratégia LogSumExp consiste em identificar o maior termo de uma somatória exponencial, considera as duas funções auxiliares $k_{s, s^{\prime}}^{\pi}$ e $K_{s}^{\pi}$, definidas por:

$$
\begin{gathered}
k_{s, s^{\prime}}^{\pi}=\ln \left[T\left(s^{\prime} \mid s, \pi(s)\right)\right]+\beta L^{\pi}(s) \\
K_{s}^{\pi}=\max _{s^{\prime} \in S}\left(k_{s, s^{\prime}}^{\pi}\right),
\end{gathered}
$$

substituindo $k_{s, s^{\prime}}^{\pi}$, na Equação 21, é obtido:

$$
\left.L^{\pi}(s)=c(s, \pi(s))\right)+\frac{1}{\beta} \ln \left[\sum_{s^{\prime} \in \mathcal{S}} \exp \left(k_{s, s^{\prime}}^{\pi}\right)\right]
$$

e introduzindo $K_{s}^{\pi}$ na Equação 24, é obtido:

$$
\begin{aligned}
L^{\pi}(s) & =c(s, \pi(s))+\frac{1}{\beta} \ln \left[\sum_{s^{\prime} \in \mathcal{S}} \exp \left(k_{s, s^{\prime}}^{\pi}-K_{s}^{\pi}\right) \cdot \exp \left(K_{s}^{\pi}\right)\right] \\
& =c(s, \pi(s))+\frac{1}{\beta} \ln \left[\exp \left(K_{s}^{\pi}\right) \cdot \sum_{s^{\prime} \in \mathcal{S}} \exp \left(k_{s, s^{\prime}}^{\pi}-K_{s}^{\pi}\right)\right] \\
& =c(s, \pi(s))+\frac{1}{\beta} K_{s}^{\pi}+\frac{1}{\beta} \ln \left[\sum_{s^{\prime} \in \mathcal{S}} \exp \left(k_{s, s^{\prime}}^{\pi}-K_{s}^{\pi}\right)\right] .
\end{aligned}
$$

Pode se obter a função valor $V^{\pi}(s)$ usando a função $L^{\pi}(s)$ por:

$$
V^{\pi}(s)=\operatorname{sgn}(\beta) \exp \left(\beta L^{\pi}(s)\right)
$$

Desta forma, ao utilizar a função $L^{\pi}(s)$ nos algoritmos de Iteração de Valor Sensível a Risco, Iteração de Política Sensível a Risco e RS-ILAO*, as políticas obtidas devem ser as mesmas que usando $V^{\pi}(s)$ nesses algoritmos. 


\section{Experimentos}

Foram realizados experimentos no Java SE 8 1.8.0_51 rodando sob o Eclipse Oxygen.3a Release (4.7.3a) em um processador Intel Core i5 de 2,6 GHz, 8 GB de memória RAM $1600 \mathrm{MHz}, 128$ GB de armazenamento SSD.

O algoritmo RS-ILAO* - proposto por este trabalho - foi analisado e os principais resultados estão descritos na Seção 5.3. A estratégia LogSumExp para GDRSMDPs também foi analisada e os resultados mais relevantes foram apresentados na Seção 5.4.

Os experimentos foram realizados no domínio de Travessia do Rio (FREIRE; DELGADO, 2017) e no domínio carteira de motorista (MINAMI; SILVA, 2013) descritos a seguir.

\subsection{Dominio da travessia do rio}

No domínio da Travessia do Rio (FREIRE; DELGADO, 2017), um robô anfíbio deve atravessar um rio. O robô deve começar a partir de uma margem esquerda até um certo ponto na margem direita. É possível atravessar o rio pela água ou através de uma ponte localizada no extremo norte. No extremo sul há uma cachoeira que, caso seja alcançada, leva o robô para o ponto de partida do percurso. É possível mover-se para as 4 direções (Norte, Oeste, Leste, Sul) ou ainda ficar parado, as ações são representadas por $\{\uparrow, \leftarrow, \rightarrow, \downarrow, \circ\}$, respectivamente. Cada ação em água tem custo $c_{a g u a}=1$ e cada ação em terra ou na ponte tem custo $c_{\text {terra }}=4$.

A Figura 5 apresenta um exemplo deste domínio em coordenadas $(x, y)$ de tamanho $14 \times 5$ e seu mapeamento em 70 estados. Os estados $(1, y)$ e $(5, y)$ representam as margens esquerda e direita, respectivamente; os estados $(1,1)$ e $(5,1)$ representam o ponto de recomeço e o final do trajeto, respectivamente; os estados $(2,14),(3,14)$ e $(4,14)$ representam a ponte disponível para travessia; os estados $(2,1),(3,1)$ e $(4,1)$ representam a cachoeira; os demais estados representam o rio.

Cada comando enviado ao robô em terra ou na ponte tem uma probabilidade de 99\% de ser obedecido e 1\% de não ser realizado por algum problema técnico, o resultado deste problema é que o robô não irá se mover e permanecerá no mesmo lugar. Cada comando enviado ao robô na água é $80 \%$ provável de ser executado com precisão e $20 \%$ 


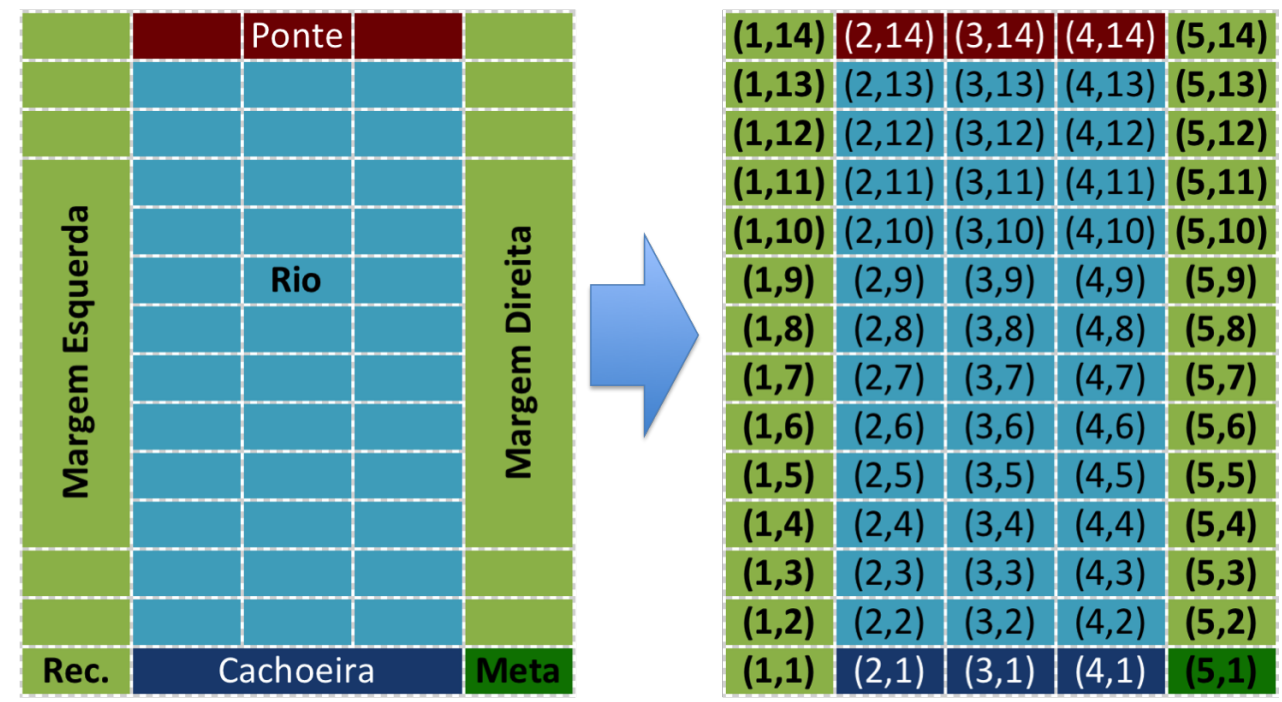

Figura 5 - Travessia do rio com grid $14 \times 5$ e seu mapeamento em estados Fonte: Elthon Manhas de Freitas, 2018

provável de não ser realizado, fazendo com que o robô seja transportado pela correnteza para a posição $(x, y-1)$. Para os experimentos foi usada a distância de Manhattan como heurística.

Se a distância para chegar na ponte for muito maior do que a largura do rio, é muito provável que um agente neutro opte por atravessar o rio em busca do menor custo médio. Se o rio for demasiado largo, este mesmo agente pode optar ir pela ponte, se o custo esperado for menor. Um agente extremamente propenso a riscos escolheria ir pelo rio independente de sua largura, uma vez que ele não está preocupado com segurança. Por outro lado, um agente extremamente averso ao risco escolheria usar a ponte por causa da segurança que esta rota proporciona.

\subsection{Domínio da carteira de motorista}

No domínio da carteira de motorista (MINAMI; SILVA, 2013; FREIRE; DELGADO, 2016) um candidato quer tirar sua habilitação para dirigir, e tem duas opções: tomar aulas ou fazer o exame prático. Para isso, quanto mais aulas ele tomar, maior é a chance de passar no exame prático. O candidato quer minimizar seu custo para levar a carta de condução. A questão para este problema é: quantas horas de aulas ele deve tomar antes de fazer o exame prático?

O candidato paga $\$ 2$ por cada exame prático e $\$ 1$ por cada hora de aula. O candidato pode fazer no máximo 4 horas de aulas antes de cada exame prático e só 
pode acumular um máximo de 10 horas de experiência. A chance de ser aprovado no exame prático depende da experiência acumulada anterior $(x)$ e do número atual de aulas recém-realizadas $(y)$. A função que retorna a probabilidade de ser aprovado no exame prático é $T(x, y)=0,08 x+0,04 y$.

Para modelar este domínio, usamos um GDRSMDP com 12 estados e 5 ações. Os estados $\{0 h, 1 h, \ldots, 10 h\}$ informam o número de horas acumuladas antes das aulas atuais e um estado de meta $s_{g}$ representa que o candidato foi aprovado. As ações $\left\{a_{0}, a_{1}, \ldots, a_{4}\right\}$ representam o número de aulas $\{0,1, \ldots, 4\}$ a serem realizadas antes de cada exame prático. A função de custo para qualquer estado $s \neq s_{g}$ é dada por $c(s, a)=2+a$. A função de transição para qualquer estado $s \neq s_{g}$ é dada pela Equação 27.

$$
T\left(s, a, s^{\prime}\right)=\left\{\begin{array}{ll}
0,08 s+0,04 a & , \text { se } s^{\prime}=s_{g} \\
1-(0,08 s+0,04 a) & , \text { se } s^{\prime}=\min \{s+a, 10\} \\
0 & , \text { nos demais casos }
\end{array} .\right.
$$

Para exemplificar as transições, a Figura 6 mostra as probabilidades de transição de acordo com as cinco ações que podem ser tomadas a partir do estado $2 \mathrm{~h}$.

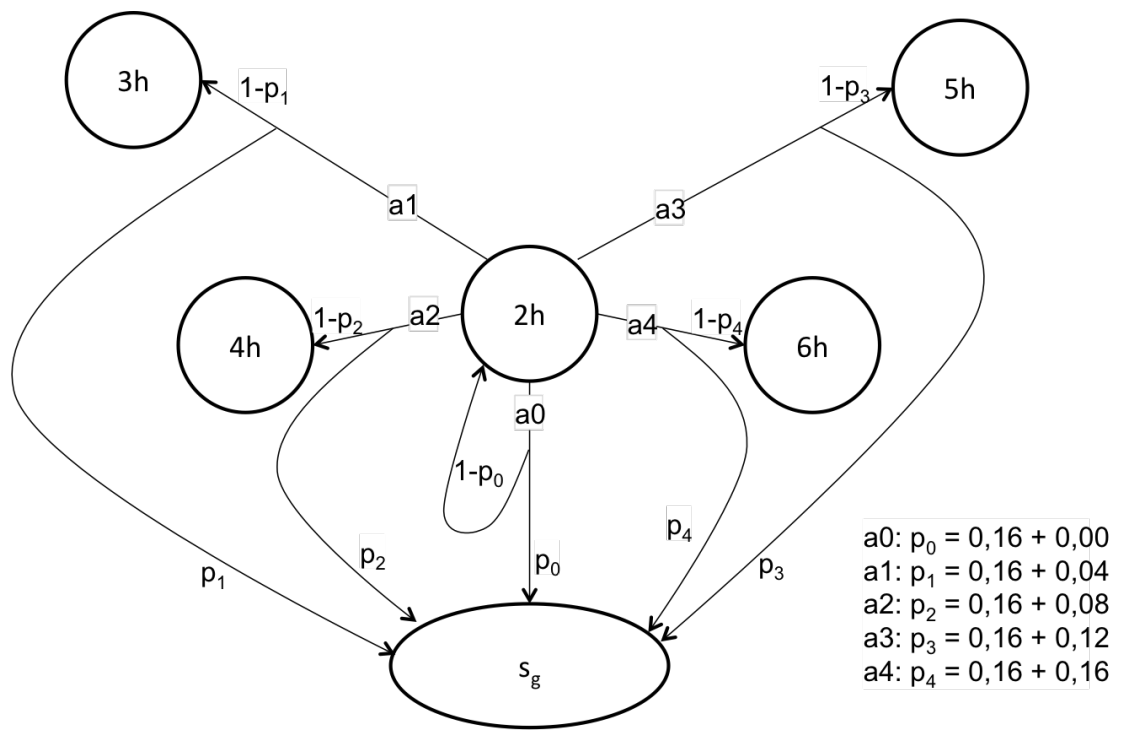

Figura 6 - Probabilidades das ações para $s=2 h$

Fonte: Elthon Manhas de Freitas, 2018

\subsection{Avaliação dos algoritmo $R S-I L A O^{*}$}

O primeiro grupo de experimentos analisa a capacidade do algoritmo RS-ILAO* encontrar políticas diferentes de acordo com o parâmetro de sensibilidade ao risco, incluindo 
a política de aversão extrema ao risco, considerando o valor de $\beta$ encontrado pelo algoritmo proposto em (FREIRE; DELGADO, 2017). O segundo grupo de experimentos compara o tempo de execução do algoritmo em função do tamanho do problema. O terceiro grupo de experimentos compara a aplicação de diferentes heurísticas. O quarto e último grupo de experimentos avalia o tempo de convergência do algoritmo para diferentes fatores de risco.

\subsubsection{Políticas obtidas}

Como esperado, o algoritmo RS-ILAO* consegue encontrar a política ótima de acordo com o fator de risco $\beta$ escolhido, isto é, quanto maior o fator de risco mais a busca por um caminho mais seguro se torna importante no momento da definição da política. Diferente do algoritmo de Iteração de Política Sensível a Risco que encontra uma política total, o algoritmo RS-ILAO* encontra uma política parcial. Além disso, foi verificado que o valor encontrado pelo RS-ILAO* para os estados pertencentes a essa política parcial são idênticos aos encontrados pelos algoritmos de Iteração de Política Sensível a Risco e Iteração de de Valor Sensível a Risco.

A Tabela 1 apresenta as políticas encontradas pelos algoritmos Iteração de Política Sensível a Risco e Iteração de Valor Sensível a Risco para o domínio de Travessia do Rio em um grid de tamanho $14 \times 5$ para seis fatores de risco diferentes. Foram considerados fatores próximos à neutralidade ao risco $(\beta=-0,0001$ e $\beta=0,0001)$, fatores propensos a risco $(\beta=-0,150$ e $\beta=-0,020)$ e fatores aversos ao risco $(\beta=+0,015, \beta=+0,030$ e $\beta=+0,070)$. Os resultados dos experimentos demonstram que para $\beta=-0,150 \mathrm{o}$ agente busca o trajeto mais barato, mesmo que seja mais arriscado; enquanto que para $\beta=+0,070$, o agente busca pela segurança da ponte, mesmo que o custo esperado desse trajeto seja muitas vezes maior do que o custo esperado do trajeto pela água. 
Tabela 1 - Políticas encontradas pelos algoritmos Iteração de Política Sensível a Risco e Iteração de Valor Sensível a Risco para o domínio Travessia do Rio em um grid $14 \times 5$ com fatores de risco $\beta$ distintos

\begin{tabular}{|c|c|c|c|c|}
\hline \multicolumn{5}{|c|}{$\beta=-0,150$} \\
\hline$\rightarrow$ & $\downarrow$ & $\downarrow$ & $\downarrow$ & $\downarrow$ \\
\hline$\rightarrow$ & $\rightarrow$ & $\rightarrow$ & $\downarrow$ & $\leftarrow$ \\
\hline$\rightarrow$ & $\rightarrow$ & $\rightarrow$ & $\downarrow$ & $\leftarrow$ \\
\hline$\rightarrow$ & $\rightarrow$ & $\rightarrow$ & $\downarrow$ & $\leftarrow$ \\
\hline$\rightarrow$ & $\rightarrow$ & $\rightarrow$ & $\downarrow$ & $\leftarrow$ \\
\hline$\rightarrow$ & $\rightarrow$ & $\rightarrow$ & $\downarrow$ & $\leftarrow$ \\
\hline$\rightarrow$ & $\rightarrow$ & $\rightarrow$ & $\downarrow$ & $\leftarrow$ \\
\hline$\rightarrow$ & $\rightarrow$ & $\rightarrow$ & $\downarrow$ & $\leftarrow$ \\
\hline$\rightarrow$ & $\rightarrow$ & $\rightarrow$ & $\downarrow$ & $\downarrow$ \\
\hline$\rightarrow$ & $\rightarrow$ & $\rightarrow$ & $\downarrow$ & $\downarrow$ \\
\hline$\rightarrow$ & $\rightarrow$ & $\rightarrow$ & $\rightarrow$ & $\downarrow$ \\
\hline$\rightarrow$ & $\rightarrow$ & $\rightarrow$ & $\rightarrow$ & $\downarrow$ \\
\hline$\rightarrow$ & $\rightarrow$ & $\rightarrow$ & $\rightarrow$ & $\downarrow$ \\
\hline$\uparrow$ & $\circ$ & $\circ$ & $\circ$ & $\circ$ \\
\hline
\end{tabular}

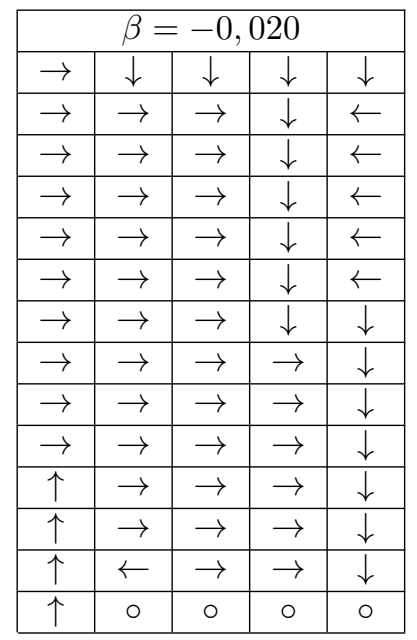

\begin{tabular}{|c|c|c|c|c|}
\hline \multicolumn{5}{|c|}{$\beta= \pm 0,0001$} \\
\hline$\rightarrow$ & $\downarrow$ & $\downarrow$ & $\downarrow$ & $\downarrow$ \\
\hline$\rightarrow$ & $\rightarrow$ & $\rightarrow$ & $\downarrow$ & $\leftarrow$ \\
\hline$\rightarrow$ & $\rightarrow$ & $\rightarrow$ & $\downarrow$ & $\leftarrow$ \\
\hline$\rightarrow$ & $\rightarrow$ & $\rightarrow$ & $\downarrow$ & $\leftarrow$ \\
\hline$\rightarrow$ & $\rightarrow$ & $\rightarrow$ & $\downarrow$ & $\leftarrow$ \\
\hline$\rightarrow$ & $\rightarrow$ & $\rightarrow$ & $\downarrow$ & $\downarrow$ \\
\hline$\rightarrow$ & $\rightarrow$ & $\rightarrow$ & $\rightarrow$ & $\downarrow$ \\
\hline$\rightarrow$ & $\rightarrow$ & $\rightarrow$ & $\rightarrow$ & $\downarrow$ \\
\hline$\rightarrow$ & $\rightarrow$ & $\rightarrow$ & $\rightarrow$ & $\downarrow$ \\
\hline$\uparrow$ & $\rightarrow$ & $\rightarrow$ & $\rightarrow$ & $\downarrow$ \\
\hline$\uparrow$ & $\rightarrow$ & $\rightarrow$ & $\rightarrow$ & $\downarrow$ \\
\hline$\uparrow$ & $\leftarrow$ & $\rightarrow$ & $\rightarrow$ & $\downarrow$ \\
\hline$\uparrow$ & $\leftarrow$ & $\rightarrow$ & $\rightarrow$ & $\downarrow$ \\
\hline$\uparrow$ & $\circ$ & $\circ$ & $\circ$ & $\circ$ \\
\hline
\end{tabular}

\begin{tabular}{|c|c|c|c|c|}
\hline \multicolumn{5}{|c|}{$\beta=+0,015$} \\
\hline$\rightarrow$ & $\downarrow$ & $\downarrow$ & $\downarrow$ & $\downarrow$ \\
\hline$\rightarrow$ & $\rightarrow$ & $\rightarrow$ & $\downarrow$ & $\leftarrow$ \\
\hline$\rightarrow$ & $\rightarrow$ & $\rightarrow$ & $\downarrow$ & $\leftarrow$ \\
\hline$\rightarrow$ & $\rightarrow$ & $\rightarrow$ & $\downarrow$ & $\leftarrow$ \\
\hline$\rightarrow$ & $\rightarrow$ & $\rightarrow$ & $\downarrow$ & $\downarrow$ \\
\hline$\rightarrow$ & $\rightarrow$ & $\rightarrow$ & $\rightarrow$ & $\downarrow$ \\
\hline$\rightarrow$ & $\rightarrow$ & $\rightarrow$ & $\rightarrow$ & $\downarrow$ \\
\hline$\uparrow$ & $\rightarrow$ & $\rightarrow$ & $\rightarrow$ & $\downarrow$ \\
\hline$\uparrow$ & $\rightarrow$ & $\rightarrow$ & $\rightarrow$ & $\downarrow$ \\
\hline$\uparrow$ & $\leftarrow$ & $\rightarrow$ & $\rightarrow$ & $\downarrow$ \\
\hline$\uparrow$ & $\leftarrow$ & $\rightarrow$ & $\rightarrow$ & $\downarrow$ \\
\hline$\uparrow$ & $\leftarrow$ & $\rightarrow$ & $\rightarrow$ & $\downarrow$ \\
\hline$\uparrow$ & $\leftarrow$ & $\rightarrow$ & $\rightarrow$ & $\downarrow$ \\
\hline$\uparrow$ & $\circ$ & $\circ$ & $\circ$ & $\circ$ \\
\hline
\end{tabular}

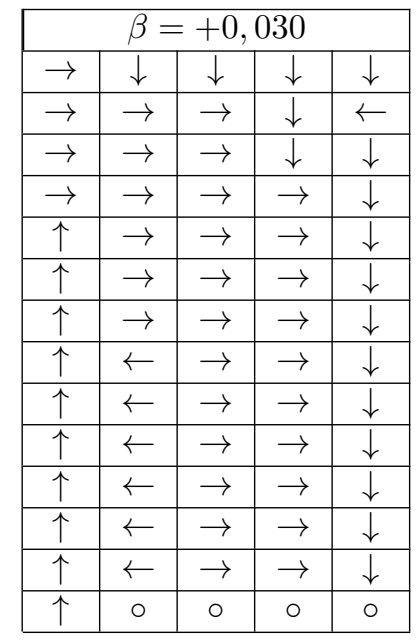

\begin{tabular}{|c|c|c|c|c|}
\hline \multicolumn{5}{|c|}{$\beta=+0,070$} \\
\hline$\rightarrow$ & $\rightarrow$ & $\rightarrow$ & $\rightarrow$ & $\downarrow$ \\
\hline$\uparrow$ & $\leftarrow$ & $\rightarrow$ & $\rightarrow$ & $\downarrow$ \\
\hline$\uparrow$ & $\leftarrow$ & $\rightarrow$ & $\rightarrow$ & $\downarrow$ \\
\hline$\uparrow$ & $\leftarrow$ & $\rightarrow$ & $\rightarrow$ & $\downarrow$ \\
\hline$\uparrow$ & $\leftarrow$ & $\rightarrow$ & $\rightarrow$ & $\downarrow$ \\
\hline$\uparrow$ & $\leftarrow$ & $\rightarrow$ & $\rightarrow$ & $\downarrow$ \\
\hline$\uparrow$ & $\leftarrow$ & $\rightarrow$ & $\rightarrow$ & $\downarrow$ \\
\hline$\uparrow$ & $\leftarrow$ & $\rightarrow$ & $\rightarrow$ & $\downarrow$ \\
\hline$\uparrow$ & $\leftarrow$ & $\rightarrow$ & $\rightarrow$ & $\downarrow$ \\
\hline$\uparrow$ & $\leftarrow$ & $\rightarrow$ & $\rightarrow$ & $\downarrow$ \\
\hline$\uparrow$ & $\leftarrow$ & $\rightarrow$ & $\rightarrow$ & $\downarrow$ \\
\hline$\uparrow$ & $\leftarrow$ & $\rightarrow$ & $\rightarrow$ & $\downarrow$ \\
\hline$\uparrow$ & $\leftarrow$ & $\rightarrow$ & $\rightarrow$ & $\downarrow$ \\
\hline$\uparrow$ & $\circ$ & $\circ$ & $\circ$ & $\circ$ \\
\hline
\end{tabular}

Fonte: Elthon Manhas de Freitas, 2018

A Tabela 2 apresenta as políticas encontradas pelo algoritmo RS-ILAO* para o mesmo tamanho de grid da Tabela 1, com os mesmos parâmetros de entrada. Como esperado, os experimentos realizados demonstram que a política resultante é uma política parcial, isto é, não contempla todos os estados, apenas os estados alcançáveis a partir do estado inicial $(1,1)$, o que é o principal responsável pelo bom desempenho do algoritmo, como será visto nas próximas seções. 
Tabela 2 - Políticas encontradas pelo algoritmo RS-ILAO* para o domínio Travessia do Rio em um grid $14 \times 5$ com fatores de risco $\beta$ distintos
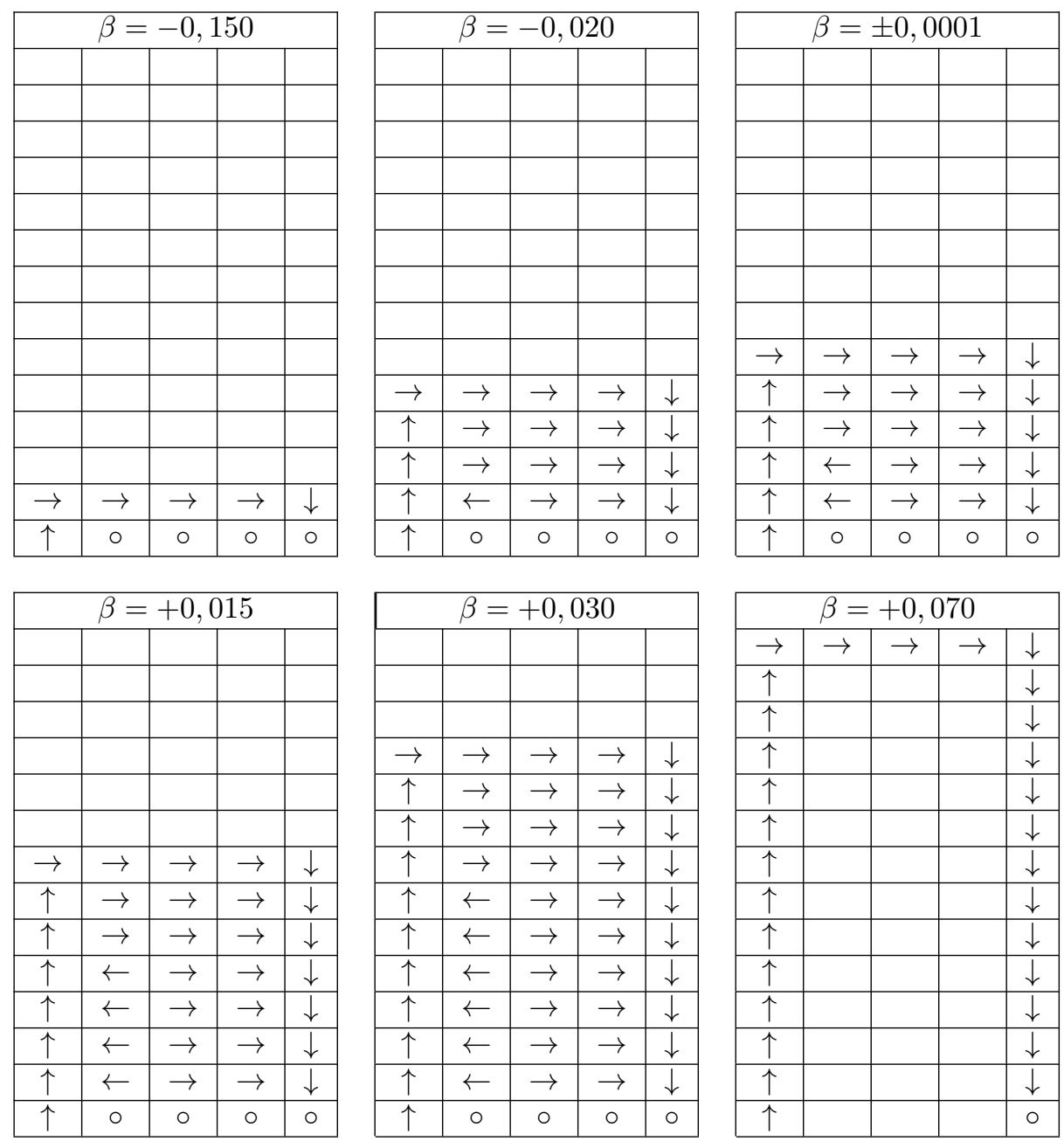

Fonte: Elthon Manhas de Freitas, 2018

A Tabela 3 apresenta as políticas encontradas pelo algoritmo RS-ILAO* para o domínio de Travessia do Rio em um grid de tamanho $20 \times 7$ para outros seis fatores de $\operatorname{risco}(\beta=-0,150, \beta=-0,005, \beta=-0,0001, \beta=0,0001, \beta=+0,020, \beta=+0,030$, $\beta=+0,040)$. Como neste o problema o rio é mais largo, mesmo com os mesmos fatores de risco utilizados no domínio anterior, o agente andará um pouco para o norte, chegando à ponte com um fator de risco menor $(\beta=0,040)$, uma vez que o risco de atravessar pelo rio agora é maior do que no domínio anterior. 
Tabela 3 - Políticas encontradas pelo algoritmo RS-ILAO* para o domínio Travessia do Rio em um grid $20 \times 7$ com fatores de risco $\beta$ distintos

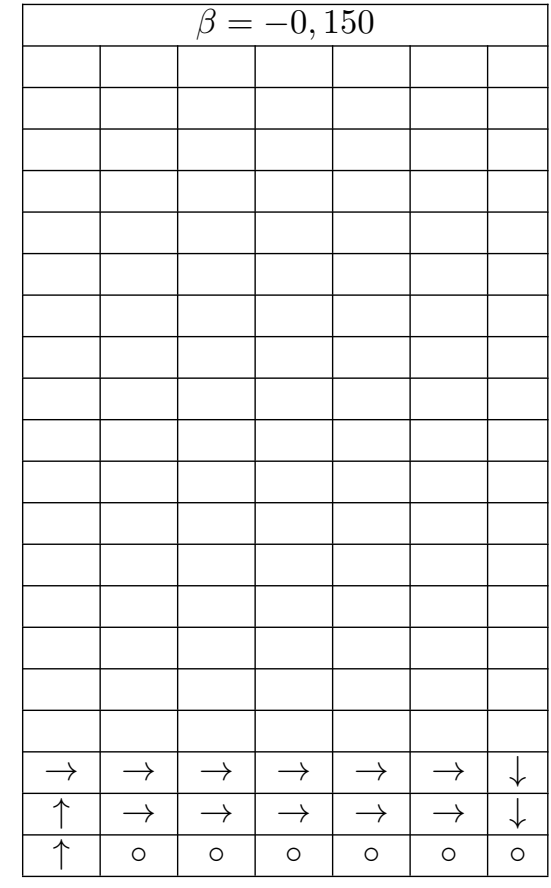

\begin{tabular}{|c|c|c|c|c|c|c|}
\hline \multicolumn{7}{|c|}{$\beta=+0,020$} \\
\hline & & & & & & \\
\hline & & & & & & \\
\hline & & & & & & \\
\hline & & & & & & \\
\hline & & & & & & \\
\hline & & & & & & \\
\hline$\rightarrow$ & $\rightarrow$ & $\rightarrow$ & $\rightarrow$ & $\rightarrow$ & $\rightarrow$ & $\downarrow$ \\
\hline$\uparrow$ & $\rightarrow$ & $\rightarrow$ & $\rightarrow$ & $\rightarrow$ & $\rightarrow$ & $\downarrow$ \\
\hline$\uparrow$ & $\rightarrow$ & $\rightarrow$ & $\rightarrow$ & $\rightarrow$ & $\rightarrow$ & $\downarrow$ \\
\hline$\uparrow$ & $\rightarrow$ & $\rightarrow$ & $\rightarrow$ & $\rightarrow$ & $\rightarrow$ & $\downarrow$ \\
\hline$\uparrow$ & $\rightarrow$ & $\rightarrow$ & $\rightarrow$ & $\rightarrow$ & $\rightarrow$ & $\downarrow$ \\
\hline$\uparrow$ & $\rightarrow$ & $\rightarrow$ & $\rightarrow$ & $\rightarrow$ & $\rightarrow$ & $\downarrow$ \\
\hline$\uparrow$ & $\rightarrow$ & $\rightarrow$ & $\rightarrow$ & $\rightarrow$ & $\rightarrow$ & $\downarrow$ \\
\hline$\uparrow$ & $\leftarrow$ & $\rightarrow$ & $\rightarrow$ & $\rightarrow$ & $\rightarrow$ & $\downarrow$ \\
\hline$\uparrow$ & $\leftarrow$ & $\rightarrow$ & $\rightarrow$ & $\rightarrow$ & $\rightarrow$ & $\downarrow$ \\
\hline$\uparrow$ & $\leftarrow$ & $\rightarrow$ & $\rightarrow$ & $\rightarrow$ & $\rightarrow$ & $\downarrow$ \\
\hline$\uparrow$ & $\leftarrow$ & $\rightarrow$ & $\rightarrow$ & $\rightarrow$ & $\rightarrow$ & $\downarrow$ \\
\hline$\uparrow$ & $\leftarrow$ & $\rightarrow$ & $\rightarrow$ & $\rightarrow$ & $\rightarrow$ & $\downarrow$ \\
\hline$\uparrow$ & $\leftarrow$ & $\leftarrow$ & $\rightarrow$ & $\rightarrow$ & $\rightarrow$ & $\downarrow$ \\
\hline$\uparrow$ & $\circ$ & $\circ$ & $\circ$ & $\circ$ & $\circ$ & $\circ$ \\
\hline
\end{tabular}
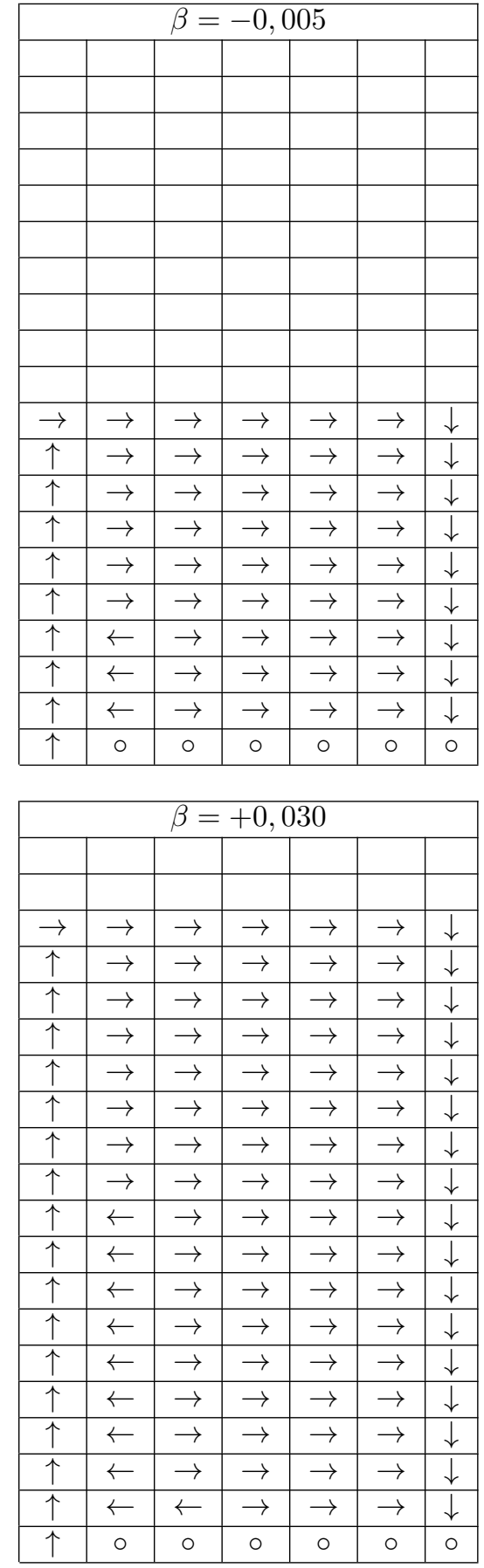

Fonte: Elthon Manhas de Freitas, 2018
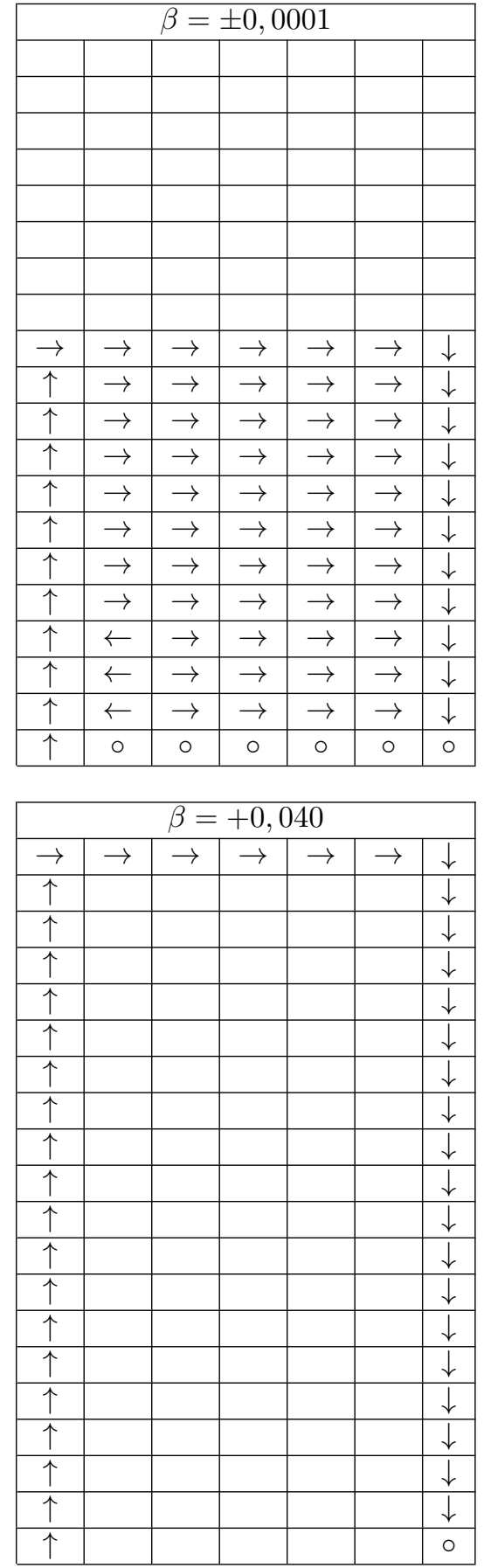

A Tabela 4 mostra as políticas resultantes geradas pelos algoritmos de Iteração de Política Sensível a Risco e Iteração de Valor Sensível a Risco no domínio da Carteira de Motorista para diferentes valores de $\beta$. Já a Tabela 5 mostra a política encontrada pelo algoritmo RS-ILAO* considerando o estado inicial $s_{0}=4 h$. Note que as políticas geradas pelos algoritmos de Iteração de Política Sensível a Risco e Iteração de Valor Sensível a 
Risco são totais, enquanto que as políticas geradas pelo algoritmo RS-ILAO* são parciais. O algoritmo RS-ILAO* calcula apenas os estados alcançáveis a partir do estado inicial, e as políticas resultantes presentes na Tabela 5 contém apenas os estados presentes no grafo da melhor solução. Por exemplo, considere o experimento 8: i) sendo $4 h$ o estado inicial do algoritmo RS-ILAO*, a ação $\pi_{8}(4 h)$ faz com que apenas os estados $s_{g}$ e $8 h$ sejam alcançáveis; ii) a partir do estado $8 h$ e $\pi_{8}(8 h)$ apenas os estados $10 h$ e $s_{g}$ podem ser alcançados; iii) a partir do estado $10 h$ e de $\pi_{8}(10 h)$, apenas o próprio estado $10 h$ e o estado $s_{g}$ podem ser alcançados; o estado $s_{g}$ é absorvente, por isso não há transição a partir de $s_{g}$. Como apenas os estados a partir de $4 h$ fazem parte do grafo da melhor solução, os demais estados não possuem política definida.

Tabela 4 - Políticas encontradas pelos algoritmos de Iteração de Política Sensível a Risco e Iteração de Valor Sensível a Risco para o domínio Carteira de Motorista com fatores de risco $\beta$ distintos

\begin{tabular}{|c|c|c|c|c|c|c|c|c|c|c|c|c|c|c|}
\hline \multirow{2}{*}{ Experimento } & \multirow{2}{*}{$\beta$} & \multicolumn{12}{|c|}{ Estados e política resultante } & \\
\hline & & $\Pi$ & Oh $1 \mathrm{~h}$ & $2 \mathrm{~h}$ & $3 \mathrm{~h}$ & $4 \mathrm{~h}$ & $5 \mathrm{~h}$ & $6 \mathrm{~h}$ & $7 \mathrm{~h}$ & $8 \mathrm{~h}$ & $9 \mathrm{~h}$ & $10 \mathrm{~h}$ & $\mathrm{~s}_{\mathrm{g}}$ & \\
\hline 1 & $-1,00$ & $\pi_{1}$ & 1 & 0 & 0 & 0 & 0 & 0 & 0 & 0 & 0 & 0 & 0 & . \\
\hline 2 & $-0,50$ & $\pi_{2}$ & 2 & 0 & 0 & 0 & 0 & 0 & 0 & 0 & 0 & 0 & 0 & - \\
\hline 3 & $-0,10$ & $\pi_{3}$ & 4 & 3 & 2 & 1 & 0 & 0 & 0 & 0 & 0 & 0 & 0 & - \\
\hline 4 & $-0,0001$ & $\pi_{4}$ & 4 & 4 & 3 & 2 & 1 & 0 & 0 & 0 & 0 & 0 & 0 & - \\
\hline 5 & 0,0001 & $\pi_{5}$ & 4 & 4 & 3 & 2 & 1 & 0 & 0 & 0 & 0 & 0 & 0 & - \\
\hline 6 & 0,10 & $\pi_{6}$ & 4 & 4 & 4 & 3 & 2 & 1 & 0 & 0 & 0 & 0 & 0 & - \\
\hline 7 & 0,50 & $\pi_{7}$ & 4 & 4 & 4 & 4 & 4 & 4 & 3 & 2 & 1 & 0 & 0 & - \\
\hline 8 & 0,80 & $\pi_{8}$ & 4 & 4 & 4 & 4 & 4 & 4 & 4 & 3 & 2 & 1 & 0 & . \\
\hline
\end{tabular}

Fonte: Elthon Manhas de Freitas, 2018

Tabela 5 - Políticas encontradas pelo algoritmo RS-ILAO* para o domínio Carteira de Motorista com fatores de risco $\beta$ distintos e com estado inicial $s_{0}=4 h$

\begin{tabular}{|c|c|c|c|c|c|c|c|c|c|c|c|c|c|c|}
\hline \multirow{2}{*}{ Experimento } & \multirow{2}{*}{$\beta$} & \multicolumn{13}{|c|}{ Estados e política resultante } \\
\hline & & $\Pi$ & $\mathbf{O h}$ & $1 \mathrm{~h}$ & $2 \mathrm{~h}$ & $3 \mathbf{h}$ & $4 \mathrm{~h}$ & $5 \mathbf{h}$ & $6 h$ & $7 \mathbf{h}$ & $8 h$ & $9 h$ & $10 \mathrm{~h}$ & $\mathrm{~s}_{\mathrm{g}}$ \\
\hline 1 & $-1,00$ & $\pi_{1}$ & - & - & - & - & 0 & - & - & - & - & - & - & - \\
\hline 2 & $-0,50$ & $\pi_{2}$ & - & - & - & - & 0 & - & - & - & - & - & - & - \\
\hline 3 & $-0,10$ & $\pi_{3}$ & - & - & - & - & 0 & - & - & - & - & - & - & - \\
\hline 4 & $-0,0001$ & $\pi_{4}$ & - & - & - & - & 1 & 0 & - & - & - & - & - & - \\
\hline 5 & 0,0001 & $\pi_{5}$ & - & - & - & - & 1 & 0 & - & - & - & - & - & - \\
\hline 6 & 0,10 & $\pi_{6}$ & - & - & - & - & 2 & - & 0 & - & - & - & - & - \\
\hline 7 & 0,50 & $\pi_{7}$ & - & - & - & - & 4 & - & - & - & 1 & 0 & - & - \\
\hline 8 & 0,80 & $\pi_{8}$ & - & - & - & - & 4 & - & - & - & 2 & - & 0 & - \\
\hline
\end{tabular}


5.3.2 Tempo de convergência para fator de risco fixo e heurística fixa

A Figura 7 apresenta uma comparação do tempo médio de convergência entre o algoritmo de Iteração de Valor Sensível a Risco, o algoritmo de Iteração de Política Sensível a Risco e o algoritmo RS-ILAO* para grids de tamanho $7 \times 3,7 \times 5,12 \times 5,14 \times 5$, $20 \times 5,20 \times 7,25 \times 7$ e $25 \times 8$ utilizando o fator de risco $\beta=0,1$ e a heurística $h_{2}$. Para calcular o tempo médio, o algoritmo foi executado 5 vezes para cada tamanho de grid. Os experimentos mostram que o algoritmo RS-ILAO* converge mais rápido que os algoritmos de Iteração de Valor Sensível a Risco e Iteração de Política Sensível a Risco para todos os tamanhos de grid, sendo até 21 vezes mais rápido para esse domínio. Os resultados estão de acordo com o esperado, uma vez que o algoritmo proposto apenas atualiza os estados alcançáveis a partir do estado inicial.

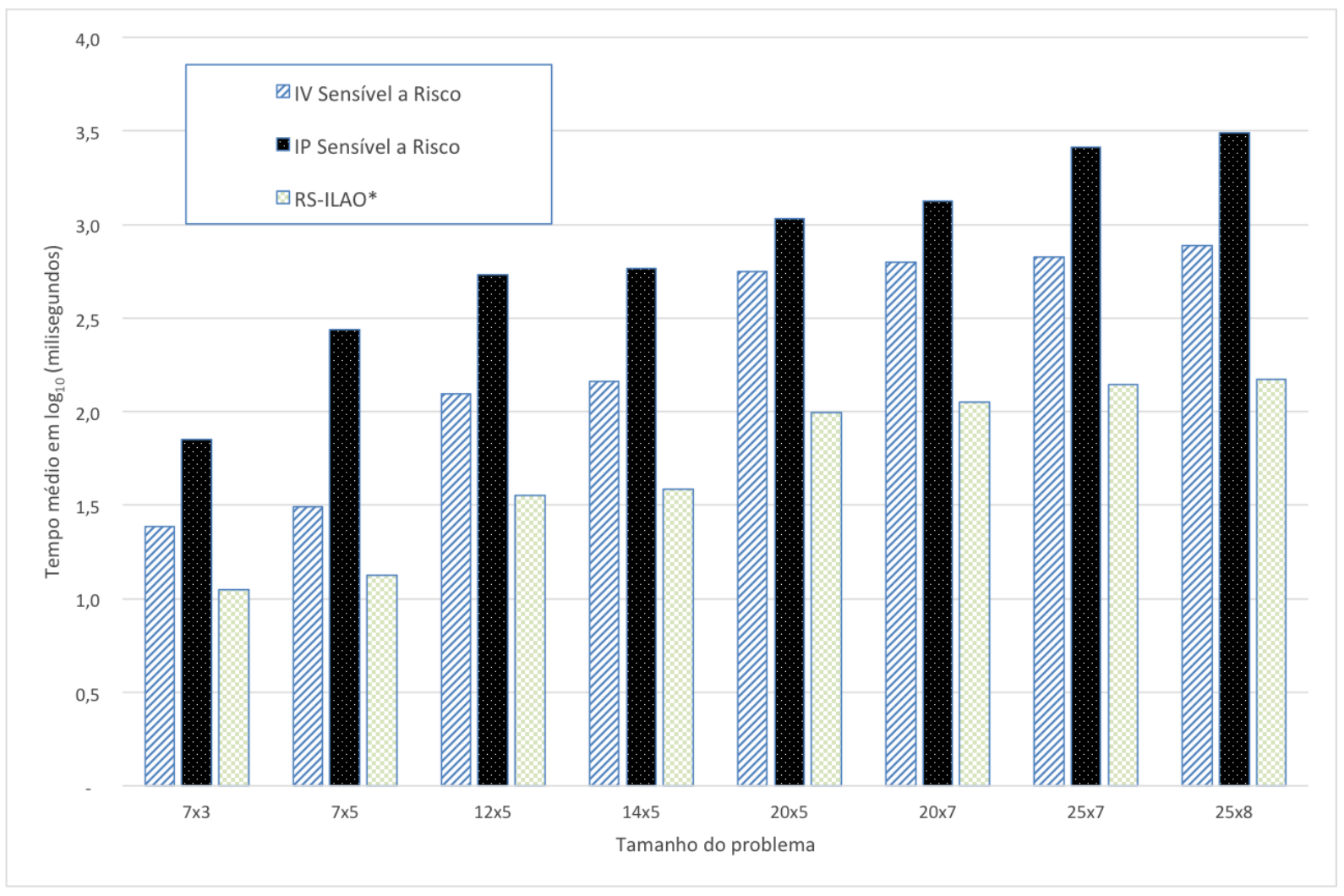

Figura 7 - Tempo médio de convergência para o Domínio de Travessia do Rio Fonte: Elthon Manhas de Freitas, 2018

5.3.3 Tempo de convergência usando diferentes heurísticas

O algoritmo RS-ILAO* foi avaliado considerando as três heurísticas $h_{1}, h_{2}$ e $h_{3}$, descritas na Seção 3.2. Na Figura 8 é mostrado o tempo médio de convergência para o 
Domínio da Travessia do Rio com problemas de tamanhos diferentes $(7 \times 3 ; 7 \times 5 ; 12 \times 5$; $14 \times 5 ; 20 \times 5 ; 20 \times 7 ; 25 \times 7 ; 25 \times 8$ e $8 \times 25)$ e com o fator de risco $\beta=0,07$. Assim como no experimento anterior, a média calculada foi baseada em 5 execuções seguidas para cada tamanho de grid.

Em todos os experimentos realizados, a heurística $h_{2}$ se mostrou mais eficiente dentre as três comparadas, pois se comparada à heurística $h_{1}$ foi a que mais se aproximou do valor final da política ótima $V^{*}(s)$, para o fator de risco utilizado. A heurística $h_{3}$, apresentou maior tempo se comparada às demais heurísticas em todas as execuções por dois fatores principais: i) foi necessário adicionar o tempo de encontrar e calcular um valor $h_{3}(s)$ baseado nos estados vizinhos $s^{\prime}$ de $s$; e ii) em estados vizinhos $s^{\prime}$ ainda não explorados, não havia um valor de referência inicializado.

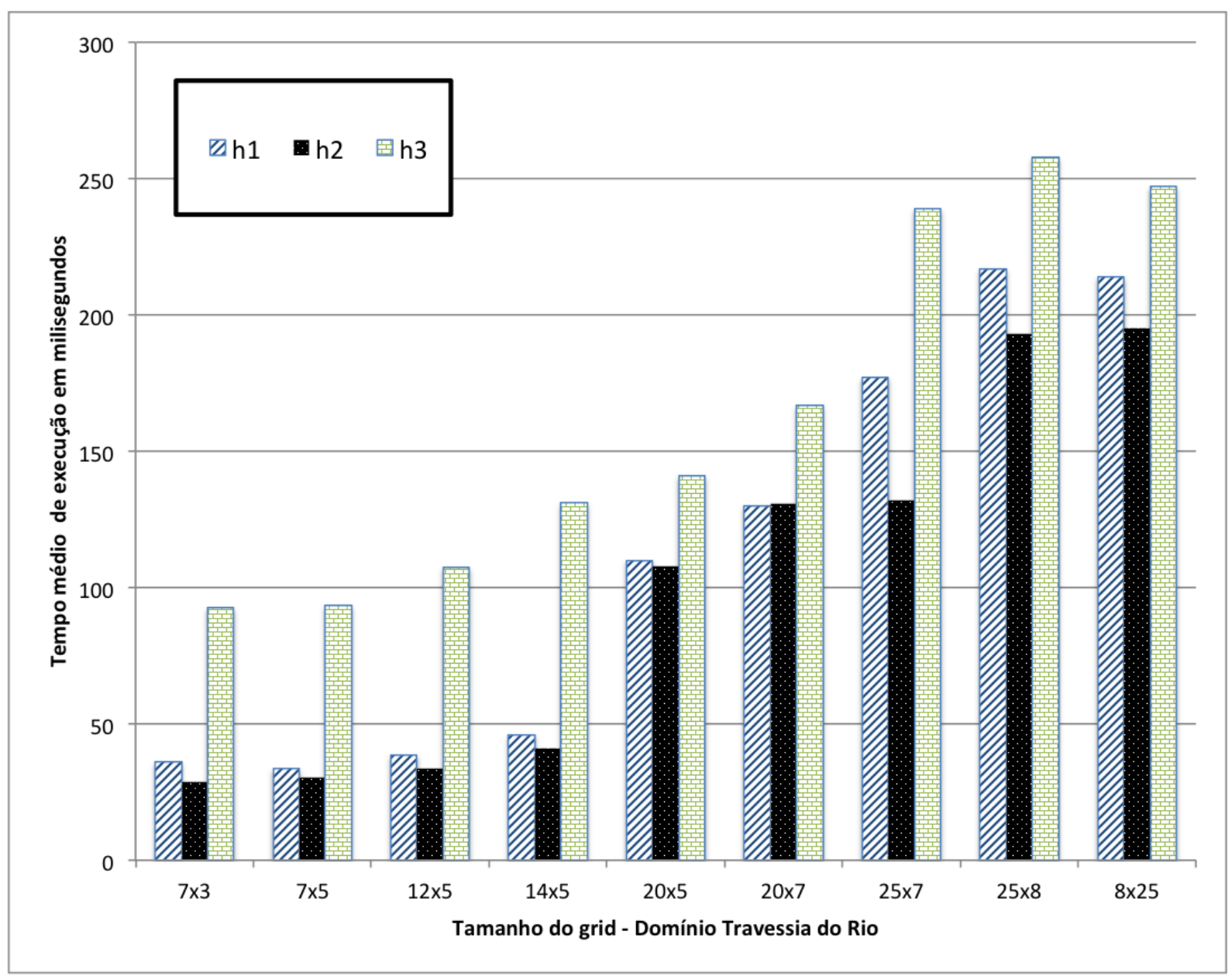

Figura 8 - Tempo médio de convergência para o Domínio de Travessia do Rio utilizando heurísticas diferentes para o RS-ILAO*

Fonte: Elthon Manhas de Freitas, 2018 
5.3.4 Tempo de convergência usando diferentes fatores de risco

A Figura 9 apresenta o tempo médio de convergência em experimentos realizados sobre o domínio da Travessia do Rio em um grid de tamanho $20 \times 8$ com fatores de risco $\beta$ distintos $(-0,5 ;-0,15 ;-0,07 ;-0,0001 ; 0,0001 ; 0,01 ; 0,02 ; 0,04 ; 0,05 ; 0,07 ; 0,08$; 0,09 e 0,15). A utilização de fatores de risco diferentes também influenciam no tempo de convergência do RS-ILAO*.

A política mais aversa possível foi obtida com o fator de risco $\beta=0,05$, o que divide o comportamento de tempo de convergência em duas sequências distintas:

- Para $-0,5 \leq \beta \leq 0,05$ : Quanto mais averso à risco, mais é necessário explorar estados para chegar à política ótima $\pi^{*}$, por isso o tempo de convergência aumenta conforme o fator de risco $\beta$ aumenta;

- Para $0,05 \leq \beta \leq 0,15$ : A política encontrada foi a mesma, sendo ela a política mais aversa possível. Para esses valores de $\beta$ o tempo de convergência começa a diminuir conforme o fator de risco $\beta$ aumenta.

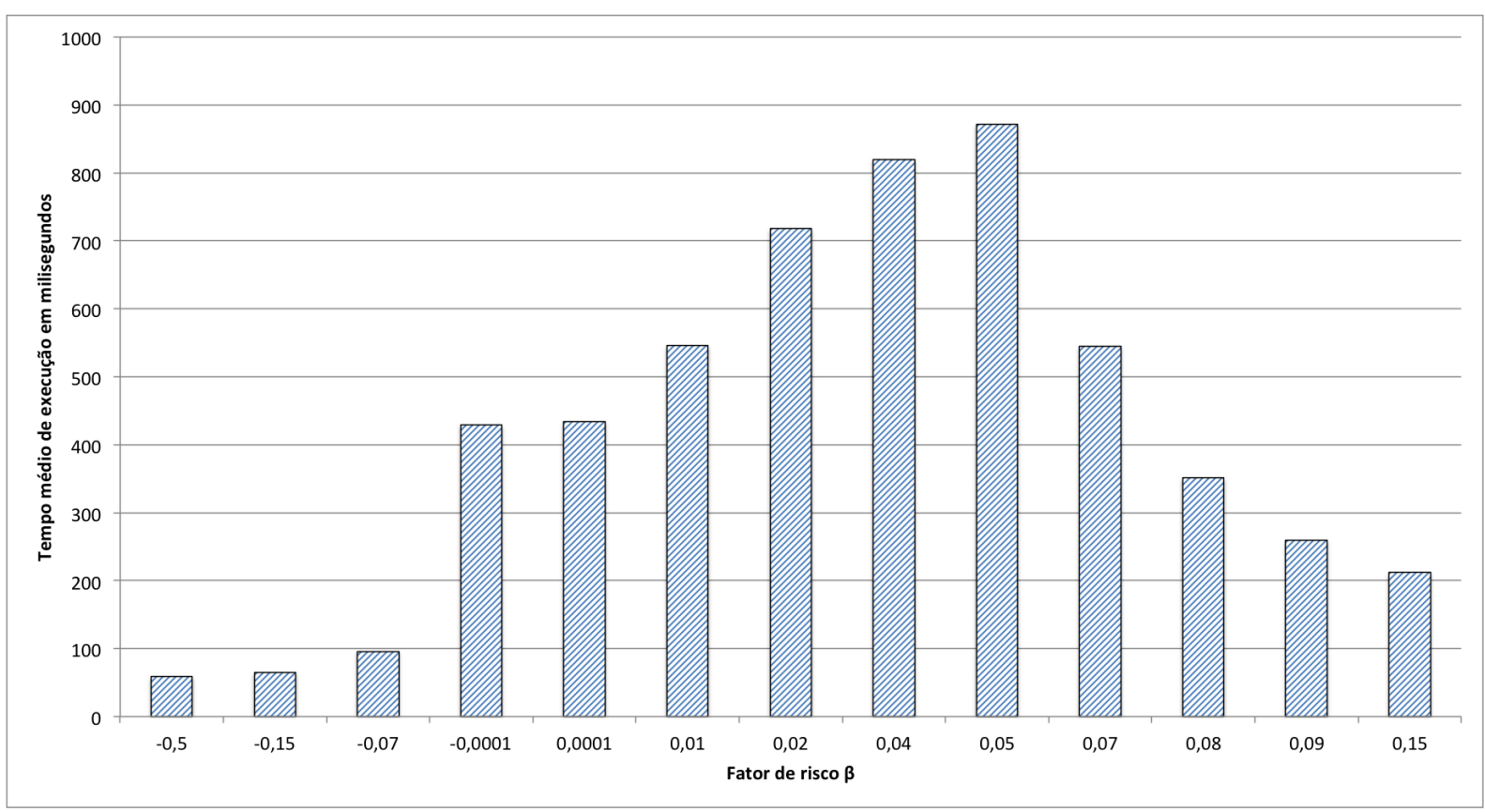

Figura 9 - Tempo médio de convergência para o Domínio de Travessia do Rio $20 \times 8$ utilizando fatores de risco diferentes para o algoritmo RS-ILAO*

Fonte: Elthon Manhas de Freitas, 2018 


\subsection{Avaliação da estratégia LogSumExp}

A utilização da função utilidade exponencial pode resultar em números com expoentes muito grandes. Ao observar a Equação 11, vemos que os seguintes componentes são responsáveis pelo valor final da função utilidade: i) o número de estados; ii) o valor da função custo $c(s, a)$; e iii) o fator de risco utilizado.

O objetivo deste experimento é identificar o aumento do tempo de processamento de acordo com o tamanho do problema e identificar situações que não podem ser resolvidos utilizando variáveis de ponto flutuante (GOLDBERG, 1991) diretamente na equação de Bellman proposta por Howard e Matheson (1972), mas que podem ser resolvidos aplicando-se a técnica LogSumExp desenvolvida no trabalho de Naylor, Donelly e Sha (2001).

A Figura 10 mostra os experimentos realizados no Domínio da Travessia do Rio com problemas de tamanhos diferentes $(7 \times 3 ; 7 \times 5 ; 12 \times 5 ; 14 \times 5 ; 20 \times 7 ; 25 \times 7 ; 25 \times 8 ; 30 \times 10$; $40 \times 20$ e $40 \times 30)$. Neste experimento, o custo em terra do domínio foi alterado para $c_{\text {terra }}=40$ com o objetivo de observar o comportamento do algoritmo de Iteração de Valor Sensível a Risco quando a função valor $V^{\pi}(s)$ apresenta expoentes muito grandes. O fator de risco utilizado foi $\beta=0,15$. Os experimentos mostraram que quanto maior o tamanho do grid, maior o tempo de convergência, independente do algoritmo utilizado. Entretanto, o tempo de convergência utilizando a estratégia LogSumExp é até duas vezes maior que o tempo de processamento do algoritmo de Iteração de Valor Sensível a Risco, quando esse último é capaz de resolver a instância. A estratégia aplicada também conseguiu resolver os mesmos problemas gerando exatamente as mesmas políticas em todos os experimentos realizados, se comparadas com o algoritmo original.

O algoritmo de Iteração de Valor sensível a risco não foi capaz de resolver as instâncias com grids maiores que $25 \times 8$. Nestes casos, a função valor $V^{\pi}(s)$ divergiu para $+\infty$ e o processamento foi interrompido. Já o mesmo algoritmo utilizando a estratégia LogSumExp conseguiu resolver todas as instâncias uma vez que ele conseguiu trabalhar com valores menores utilizando $L^{\pi}(s)$. 


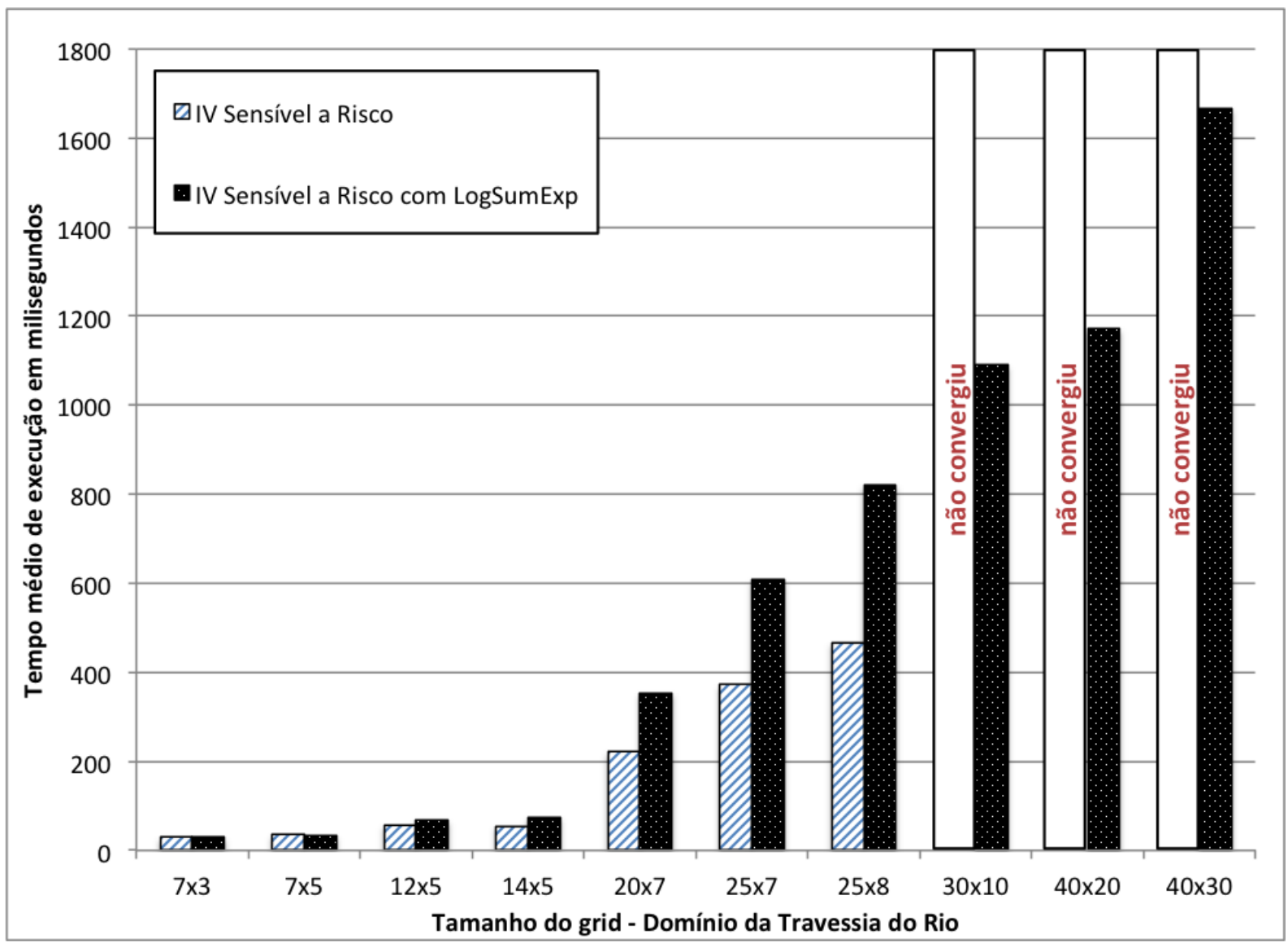

Figura 10 - Tempo médio de convergência para o Domínio de Travessia do Rio utilizando Iteração de Valor Sensível a Risco e Iteração de Valor Sensível a Risco com a estratégia LogSumExp

Fonte: Elthon Manhas de Freitas, 2018

\subsection{Considerações finais}

Neste capítulo foram realizados experimentos no domínio de Travessia do Rio e no domínio da Carteira de Motorista para analisar a capacidade do algoritmo RS-ILAO* de encontrar políticas diferentes de acordo com o fator de risco $\beta$ utilizado. Os experimentos mostram que: (i) o algoritmo RS-ILAO* consegue encontrar políticas ótimas parciais para esse domínio de acordo com o valor $\beta$ escolhido, além de ser até 21 vezes mais rápido que o algoritmo de Iteração de Política Sensível a Risco e até 5,5 vezes mais rápido que o algoritmo de Iteração de Valor Sensível a Risco; e (ii) a utilização da técnica chamada LogExpSum em algoritmos que resolvem GDRSMDPs possibilita obter políticas estacionárias para domínios que antes divergiam devido a limitações de representação de ponto flutuante do ambiente computacional. 


\section{Conclusões e trabalhos futuros}

Neste capítulo são apresentadas as principais contribuições do trabalho, as publicações geradas, bem como o direcionamento inicial para os trabalhos futuros.

\subsection{Resumo das contribuições}

Neste trabalho foi proposto um algoritmo heurístico chamado RS-ILAO* que utiliza função exponencial como forma de modelar as atitudes em relação ao risco. Como apenas os estados relevantes, a partir do estado inicial, são atualizados, este algoritmo se mostrou muito mais eficiente se comparado aos algoritmos estado-da-arte.

Como os trabalhos da literatura para GDRSMDPs não se preocupam com a implementação em um ambiente computacional, foi necessário identificar, avaliar e implementar uma técnica (a técnica LogExpSum) que permitisse operar números de expoentes que extrapolam limites de ambientes computacionais tradicionais.

Desta forma, com a aplicação de técnicas utilizadas na área de planejamento probabilístico aliadas às técnicas para lidar com o processamento de números com expoentes muito elevados, vemos um campo de oportunidades abertas à exploração da função utilidade exponencial como modeladora de risco, até então pouco explorada.

\subsection{Publicações geradas}

As publicações geradas durante o período do mestrado são:

- Título: Processos de decisão de Markov com sensibilidade a risco com função de utilidade exponencial: Uma revisão sistemática da literatura.

Autores: Elthon Manhas de Freitas, Karina Valdivia Delgado, Valdinei Freire da Silva

Data de publicação: 05/jun/2017

Título da conferência: XIII Simpósio Brasileiro de Sistemas de Informação Trilha da conferência: Trilha Principal

- Título: Planejamento Probabilístico Sensível a Risco com ILAO* e Função Utilidade Exponencial. 
Autores: Elthon Manhas de Freitas, Karina Valdivia Delgado, Valdinei Freire da Silva

Artigo aceito: 10/ago/2018

Título da conferência: XV Encontro Nacional de Inteligência Artificial e Computacional (ENIAC)

Trilha da conferência: Trilha Principal

\subsection{Trabalhos futuros}

Entre os possíveis trabalhos futuros estão:

- Aplicação do algoritmo proposto em outros domínios. Isso porque com a otimização de processamento e a possibilidade de implementação em ambientes computacionais, os problemas tradicionais de GDMDPs agora podem ser modelados como GDRSMDPs que utilizam função exponencial.

- Adaptação dos algoritmos que resolvem GDRSMDPS para considerar estados a partir dos quais não é possível alcançar os estados meta, também conhecidos como deadends. 


\section{Referências $^{1}$}

BERNOULLI, D. Exposition of a new theory on the measurement of risk. Econometrica, v. 22, n. 1, p. 23-36, 1954. Citado 2 vezes nas páginas 26 e 37.

BERTSEKAS, D. P.; TSITSIKLIS, J. N. An analysis of stochastic shortest path problems. Mathematics of Operations Research, INFORMS, Institute for Operations Research and the Management Sciences (INFORMS), Linthicum, Maryland, USA, v. 16, n. 3, p. 580-595, ago. 1991. ISSN 0364-765X. Disponível em: 〈http://dx.doi.org/10.1287/moor.16.3.580〉. Citado 3 vezes nas páginas 20, 23 e 24 .

CHEN, Y.; GAO, D. Y. Global solutions to nonconvex optimization of 4th-order polynomial and log-sum-exp functions. Journal of Global Optimization, Springer, v. 64, n. 3, p. 417-431, 2016. Citado na página 37.

DELAGE, E; MANNOR, S. Percentile optimization for Markov decision processes with parameter uncertainty. Operations research, INFORMS, v. 58, n. 1, p. 203-213, 2010. Citado na página 17.

DENARDO, E. V.; ROTHBLUM, U. G. Optimal stopping, exponential utility, and linear programming. Mathematical Programming, v. 16, n. 1, p. 228-244, 1979. Citado na página 18.

FILAR, J. A.; KALLENBERG, L. C. M.; LEE, H.-M. Variance-penalized Markov decision processes. Mathematics of Operations Research, v. 14, n. 1, p. 147-161, 1989. Citado na página 18.

FILAR, J. A. et al. Percentile performance criteria for limiting average Markov decision processes. IEEE Transactions on Automatic Control, v. 40, n. 1, p. 2-10, 1995. Citado na página 18.

FREIRE, V.; DELGADO, K. V. Extreme risk averse policy for goal-directed risk-sensitive Markov decision process. In: IEEE. 5th Brazilian Conference on Intelligent Systems (BRACIS). Recife, PE, Brazil, 2016. p. 79-84. Citado 3 vezes nas páginas 18, 28 e 41.

FREIRE, V.; DELGADO, K. V. GUBS: A utility-based semantic for goal-directed Markov decision processes. In: Proceedings of the 16th Conference on Autonomous Agents and MultiAgent Systems. [S.1.: s.n.], 2017. p. 741-749. Citado 3 vezes nas páginas 18, 40 e 43.

FREITAS, E. M. de; DELGADO, K. V.; FREIRE, V. Processos de decisão de Markov com sensibilidade a risco com função de utilidade exponencial: Uma revisão sistemática da literatura. In: BRAZILIAN COMPUTER SOCIETY. Lavras, MG, Brazil, 2017. Citado 2 vezes nas páginas 19 e 37.

GEFFNER, H.; BONET, B. A concise introduction to models and methods for automated planning. Synthesis Lectures on Artificial Intelligence and Machine Learning, Morgan \& Claypool Publishers, v. 8, n. 1, p. 1-141, 2013. Citado na página 20.

GOLDBERG, D. What every computer scientist should know about floating-point arithmetic. ACM Computing Surveys (CSUR), ACM, v. 23, n. 1, p. 5-48, 1991. Citado 2 vezes nas páginas 37 e 51.

1 De acordo com a Associação Brasileira de Normas Técnicas. NBR 6023. 
HANSEN, E. A.; ZILBERSTEIN, S. Heuristic search in cyclic and/or graphs. In: AAAI/IAAI. Madison, Wisconsin: Association for the Advancement of Artificial Intelligence, 1998. p. 412-418. Citado na página 24.

HANSEN, E. A.; ZILBERSTEIN, S. LAO*: A heuristic search algorithm that finds solutions with loops. Artificial Intelligence, v. 129, n. 1, p. 35 - 62, 2001. Citado 3 vezes nas páginas 24, 29 e 33.

HOWARD, R. A.; MATHESON, J. E. Risk-sensitive Markov decision processes. Management science, INFORMS, v. 18, n. 7, p. 356-369, 1972. Citado 4 vezes nas páginas 18, 26, 37 e 51.

JAQUETTE, S. C. A utility criterion for Markov decision processes. Management Science, INFORMS, v. 23, n. 1, p. 43-49, 1976. Citado na página 18.

KAHNG, A. B.; WANG, Q. A faster implementation of aplace. In: ACM. Proceedings of the 2006 international symposium on Physical design. 200 Edenvale Avenue, San Jose, CA 95136, USA, 2006. p. 218-220. Citado na página 37.

KEENEY, R. L.; RAIFFA, H. Decisions with Multiple Objectives: Preferences and Value Tradeoffs. New York: Wiley, 1976. Citado na página 25.

KENNINGS, A. A.; MARKOV, I. L. Analytical minimization of half-perimeter wirelength. In: ACM. Proceedings of the 2000 Asia and South Pacific Design Automation Conference. [S.l.], 2000. p. 179-184. Citado na página 37.

MINAMI, R.; SILVA, V. F. da. Shortest stochastic path with risk sensitive evaluation. In: 11th Mexican International Conference on Artificial Intelligence, MICAI. San Luis Potosí, Mexico: Springer Berlin Heidelberg, 2013. p. 371-382. Citado 2 vezes nas páginas 40 e 41.

MOLDOVAN, T. M.; ABBEEL, P. Risk aversion in Markov decision processes via near optimal Chernoff bounds. In: Advances in Neural Information Processing Systems, NIPS 2012. Harrah's Lake Tahoe, U.S. 50, Stateline, NV, EUA: Neural Information Processing Systems, 2012. p. 3131-3139. Citado na página 17.

NAYLOR, W. C.; DONELLY, R.; SHA, L. Non-linear optimization system and method for wire length and delay optimization for an automatic electric circuit placer. Google Patents, out. 9 2001. US Patent 6,301,693. Citado 2 vezes nas páginas 37 e 51.

NIELSEN, F.; SUN, K. Guaranteed bounds on information-theoretic measures of univariate mixtures using piecewise log-sum-exp inequalities. Entropy, Multidisciplinary Digital Publishing Institute, v. 18, n. 12, p. 442, 2016. Citado na página 37.

NILSSON, N. J. Principles of artificial intelligence. Palo Alto, CA: Tioga Publishing, 1980. Citado na página 24.

PATEK, S. D. On terminating Markov decision processes with a risk-averse objective function. Automatica, Elsevier, v. 37, n. 9, p. 1379-1386, 2001. Citado 3 vezes nas páginas 18, 27 e 28.

PUTERMAN, M. L. Markov Decision Processes: Discrete Stochastic Dynamic

Programming. 1st. ed. New York, NY: John Wiley \& Sons, 1994. ISBN 0471619779.

Citado 2 vezes nas páginas 17 e 23. 
ROBERT, C. Machine learning, a probabilistic perspective. CHANCE, Taylor Francis, v. 27, n. 2, p. 62-63, 2014. Citado na página 37.

ROTHBLUM, U. G. Multiplicative Markov decision chains. Mathematics of Operations Research, v. 9, n. 1, p. 6-24, 1984. Citado na página 18.

SIGL, G.; DOLL, K.; JOHANNES, F. M. Analytical placement: A linear or a quadratic objective function. In: ACM. Proceedings of the 28th ACM/IEEE Design Automation Conference. San Francisco, CA, USA, 1991. p. 427-432. Citado na página 37.

SOBEL, M. J. The variance of discounted Markov decision processes. Journal of Applied Probability, Applied Probability Trust, v. 19, n. 4, p. 794-802, 1982. Citado na página 18. 